Alma Mater Studiorum - Università di Bologna DEPARTMENT OF ECONOMICS

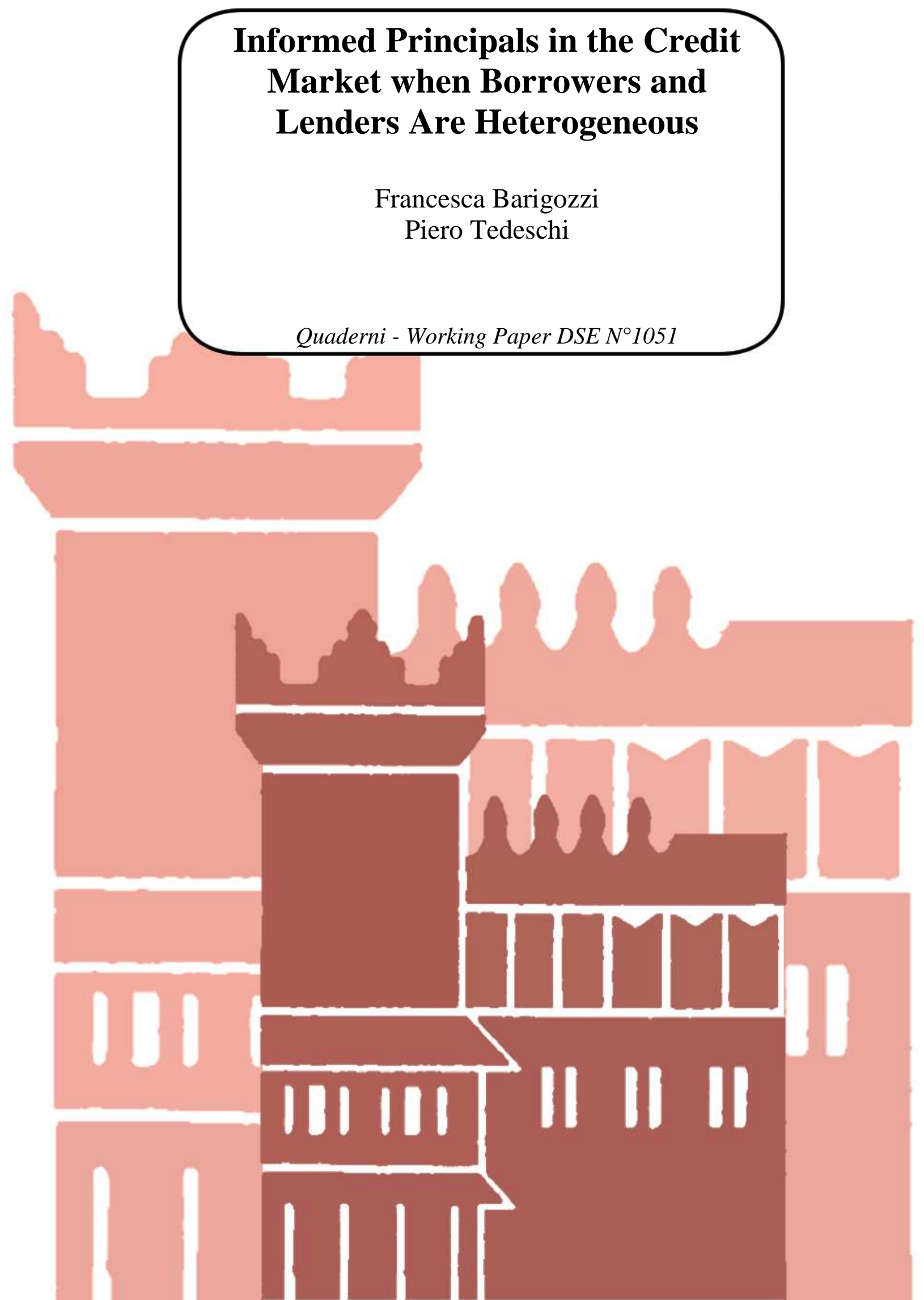




\title{
Informed Principals in the Credit Market when Borrowers and Lenders Are Heterogeneous
}

\author{
Francesca Barigozzi* \\ Piero Tedeschi ${ }^{\dagger}$ \\ University of Bologna \\ Università Cattolica del Sacro Cuore - Milano \\ January 2016
}

\begin{abstract}
Both borrowers and lenders can be socially responsible (SR). Ethical banks commit to financing only ethical projects, which have social profitability but lower expected revenues than standard projects. Instead, no credible commitment exists for SR borrowers.

The matching between SR borrowers and ethical banks reduces the frictions caused by moral hazard. However, when the type of the borrowers is not observable, then standard borrowers have incentives to invest in ethical projects pretending to be SR. We show that the separation of borrowers entails costs that are paid by SR entrepreneurs but are relatively low because standard lenders offer an outside option that relaxes the self-selection constraint of the borrowers.

Technically, we solve a Contract Proposal Game where informed principals (borrowers) offer different menus of contracts to heterogeneous agents (banks). We show that market segmentation improves efficiency and solves the problem of multiplicity of equilibria in Contract Proposal Games.
\end{abstract}

Jel classification: D86, G21, G30.

Key-words: corporate social responsibility, ethical banks, motivated borrowers, informed principals, moral hazard, adverse selection.

\footnotetext{
${ }^{*}$ Department of Economics, University of Bologna and CHILD, P.zza Scaravilli 2, 40126 Bologna (Italy). E-mail: francesca.barigozzi@unibo.it

${ }^{\dagger}$ Department of Economics and Finance Università Cattolica del Sacro Cuore di Milano. E-mail: piero.tedeschi@unicatt.it
} 


\section{Introduction}

The emergence of ethical banks is an expression of the growing demand for corporate social responsibility (CSR) in the banking industry of developed countries. Quoting Bénabou and Tirole (2010, p.2), CSR "is about sacrificing profits in the social interest. For there to be a sacrifice, the firm must go beyond its legal and contractual obligations, on a voluntary basis. CSR embraces a wide range of behaviors, such as being employee friendly, environment friendly, mindful of ethics, respectful of communities where the firm's plants are located, and even investor friendly". In line with the previous definition, we interpret ethical banks as socially responsible lenders, because they commit to fund only socially relevant projects, i.e. ethical projects, which provide both social and economic advantages, but which deliver lower expected revenue than standard ones. Ethical banks are not the only socially responsible agents in the credit market of high income countries, we call "motivated" those borrowers that prefer to engage in socially valuable activities as ethical projects because, by doing so, they receive a non-monetary premium for social responsibility. Contrary to ethical banks, motivated borrowers do not commit to ethical projects and will still invest in standard projects if their expected return is sufficiently higher than the one of ethical projects. ${ }^{1}$

Barigozzi and Tedeschi (2015) show that the assortative matching between ethical banks and motivated borrowers allows to reduce the frictions caused by moral hazard. The efficiency gain can be so high that motivated borrowers trading with ethical banks end up receiving better contract conditions than standard borrowers trading with commercial banks. Better prospects translate in larger loans, higher expected returns for the borrower and lower interest rates and are possible when the premium for social responsibility is sufficiently high. Such a premium accrues motivated entrepreneurs' payoffs when they undertake an ethical project financed by an ethical bank and the project turns out to be successful. Importantly, the surplus arising from the matching between agents caring about social issues implies that socially responsible banks, despite the fact of sacrificing profits on a voluntary basis, can survive in the long run as well as traditional lenders. Some recent empirical studies focusing on ethical banks (Becchetti et al. 2011; Becchetti and Garcia 2011; Cornée and Szafarz 2012) are in line with the previous results: ethical banks authorize larger loans than commercial banks, and borrowers financed by ethical banks, having controlled for borrowers' characteristics, are charged a lower interest rate.

In our previous paper we investigate how socially responsible lenders and motivated borrowers interact with each other when they participate in a credit market where standard lenders and borrowers also operate and moral hazard is the unique market failure, meaning that both borrowers and lenders' characteristics are common knowledge. As already mentioned, in the previous paper we proved that motivated borrowers can obtain better credit conditions than other borrowers if the premium for social responsibility is sufficiently high.

Suppose, now, that borrowers' motivation is private information and no credible commitment is

\footnotetext{
${ }^{1}$ We refer the reader to Barigozzi and Tedeschi (2015) for the description of the typical mission of ethical banks, for real world examples and for a discussion about ethical projects, ethical banks and motivated borrowers.
} 
available to entrepreneurs so that their pro-social attitude can be falsified. In particular, a borrower could pretend to be socially responsible in order to strengthen its bargaining position. This is precisely what happens in our framework where standard borrowers are the "bad" types willing to take advantage of their private information. In our setting, falsifying borrowers' CSR is straightforward because entrepreneurs pretending to be motivated simply have to undertake ethical projects financed by ethical banks. This has, however, negative implications for ethical lenders as, when a standard entrepreneur mimics a motivated one, he/she possibly misbehaves and the lending contract is not profitable anymore for the bank. The situation we describe may occur in a market where borrowers are start-ups, or new firms lacking a reputation and credible commitment to CSR does not exist.

To sum up, in this paper we analyze the interaction between heterogeneous borrowers and heterogeneous lenders in a credit market where both moral hazard and adverse selection on the borrowers' side have bite because banks are not able to observe borrowers' behavior nor they can distinguish motivated from standard borrowers.

We show that, under moral hazard and adverse selection, the benefit arising from trade between ethical banks and motivated borrowers is partially offset by the information rent appropriated by standard borrowers. In particular, the equilibrium outcome is such that standard borrowers sign with commercial banks the same contract as under moral hazard only; whereas motivated borrowers trading with ethical banks preserve their higher borrowing capacity but loose the benefit of better contract conditions. In different words, motivated borrowers pay the cost of separation by accepting contractual terms that do not appeal to a standard entrepreneur. Moreover, as under moral hazard only, the market is fully segmented, meaning that standard agents trade among themselves in the market for standard projects while ethical banks trade with motivated borrowers in the market for ethical projects.

Turning to the modeling strategy, we study a model where borrowers are the informed party proposing contracts to lenders. Moreover, as it will be better argued in Subsection 4.1, the type of borrowers affects the ethical banks profits, through the solution of the moral hazard problem, making our model a common value one. We are thus in a framework with informed principals and common values and, borrow from the seminal paper by Maskin and Tirole (1992).

In Maskin and Tirole (1992), heterogeneous principals propose one single menu of contracts to uninformed and uniform agents and a key-concept in the paper is the Rothschild-Stliglitz-Wilson (RSW) allocation (with homogeneous agents). Such allocation indicates the menu of incentive compatible contracts that are profitable type-by-type and allow separation at the lowest cost. ${ }^{2}$ Conversely, in our model heterogeneous principals (borrowers) propose contracts to uninformed and heterogeneous agents (lenders). The important difference is that, in our Contract Proposal Game, informed principals offer two

\footnotetext{
${ }^{2}$ Maskin and Tirole (1992) name the RSW allocation, where the incentive-compatible contracts are profitable type-bytype, after the influential papers by Rothschild and Stiglitz (1976) and Wilson (1977). As we will further discuss in the paper, informed principals can always guarantee themselves the payoff reached with the RSW allocation which is the unique equilibrium when it is interim efficient. When it is not, then multiplicity of equilibria arises in the contract proposal game.
} 
menus (one for each type of agents), instead of only one. ${ }^{3}$ We show that all contracts in the two menus break-even type-by-type and that the menu for ethical lenders contains the RSW allocation with market segmentation (see below). Instead, the menu for standard lenders always contains a pooling contract, since for standard lenders the two types of borrowers are equivalent, as it will be clear in what follows. ${ }^{4}$ Once each type of agents (lenders) has accepted the menu designed for it, each informed principal (borrower) selects the preferred option among the contracts available in the two menus. More specifically, each borrower picks the overall preferred contract from one menu and the null contract from the other menu. We first show that the presence of heterogeneous lenders and the fact of offering them two different menus lead to a substantial improvement in the efficiency of the equilibrium allocation and guarantees its uniqueness. Finally, we show that a sufficient condition for the unique equilibrium outcome to be interim efficient is that the share of motivated borrowers in the population of investors is lower than $50 \%$.

As for efficiency, the cost of separation would be higher if ethical banks were the unique type of lenders in the credit market. Intuitively, in the RSW allocation with market segmentation contained in the menu for ethical banks, borrowers take into account that trading with standard lenders represents an outsideoption that relaxes the self-selection constraint and helps preventing standard borrowers from mimicking motivated entrepreneurs. We thus conclude that the RSW allocation with market segmentation Paretodominates the RSW allocation with homogeneous lenders. Moreover, in the model with homogeneous agents, the RSW allocation is always an equilibrium. In our setting with heterogeneous agents, instead, the equilibrium delivers market segmentation and the RSW allocation with market segmentation is not an equilibrium outcome ${ }^{5}$. Indeed, only motivated borrowers pick the contract contained in the RSW allocation inside the menu for ethical banks, whereas standard borrowers pick the contract appearing in the menu offered to standard lenders. Hence, the RSW allocation with market segmentation contains a latent contract.

As for uniqueness, the existence of two menus designed for the two types of lenders and the fact that cross-subsidies between different menus are impossible (meaning that transfers between different lenders are not feasible ${ }^{6}$ ), imply that the uniqueness issue is fully solved. Only cross-subsidies inside the menu for ethical banks make sense in our setting. To prove uniqueness we thus show that, in the menu for ethical banks, it is impossible to design separating contracts with cross-subsidies that Pareto dominate the equilibrium allocation with market segmentation. Hence, we conclude that the equilibrium outcome with market segmentation is necessarily unique. Finally, we study the efficiency properties of the unique

\footnotetext{
${ }^{3}$ Each menu also contains the null contract which works as an "exit option" and allow for market segmentation.

${ }^{4}$ In particular, the menu offered to ethical banks contains two self-selecting contracts and the null one. The menu for standard lenders contains, instead, a pooling contract together with the null one.

${ }^{5}$ We thus distinguish between the $R S W$ allocation with market segmentation and the equilibrium allocation with market segmentation. The latter contains only one contract from the RSW allocation with market segmentation (the one designed for motivated borrowers).

${ }^{6}$ With cross-subsidies among banks, the menu designed for the standard bank would contain a pooling contract letting the bank earn negative profits to be covered with positive profits earned by the ethical bank in the other menu. But, in the second stage of the Contract Proposal Game, the standard lender would not accept a menu entailing negative profits.
} 
equilibrium outcome and find a sufficient condition such that the latter is interim efficient (meaning that, in the hypothetical case where transfers between different menus were feasible, no dominating contracts with cross-subsidies would exist). More specifically, a sufficient condition for the equilibrium with market segmentation to be interim efficient is that the share of motivated borrowers in the population of potential borrowers is less than $50 \%$.

To sum up, our results show that the existence of heterogeneous agents receiving different menus and the fact that transfers between the different menus are not feasible, improve efficiency and solve the problem of multiplicity of equilibria in games with informed principals.

Our paper is related to the small literature on CSR in the credit market of high-income countries. Few works, mainly in the business literature, analyze ethical banks and show the relevant role of ethical banking as an independent activity (e.g., Green 1989; Lynch, 1991; San-Jose et al., 2009).

From the point of view of the modelling strategy, the setting we study borrows from Tirole (2006). The paper is also related to the models dealing with signaling and informed principals in the credit market that are superbly reviewed in the same book (Tirole 2006, chapter 6). In those studies, good borrowers try to signal attractive prospects to investors by introducing distortions that are costly to them but would be even costlier to bad borrowers; the informed party can act as a principal by proposing the contract (as in our model) or can accept the contract offered by the uninformed party. ${ }^{7}$ Notable and more recent examples of this kind of literature are Henessy et al. (2010), Cestone et al. (2014) and Bouvard (2014), all dealing with problems not closely related with ours.

Even if the idea that a firm can follow CSR to strengthen its market position is not new (see the excellent review on the economics of CSR by Kitzmueller and Shimshack 2012), to the best of our knowledge our paper is the first studying a situation where no available commitment to CSR exists such that a borrower can falsify its interest for social issues.

Our paper is organized as follows. Section 2 describes the model set-up and the payoffs of socially responsible lenders and motivated borrowers. In Section 3, we show how the matching between socially responsible agents relaxes the incentive compatible constraint of motivated borrowers and we briefly report results from Barigozzi and Tedeschi (2015) about the characterization of loan agreements offered in the credit market under moral-hazard only. Section 4 solves the model with both moral-hazard and adverse selection. More specifically, Subsection 4.1 defines the RSW allocation with market segmentation, shows the efficiency gain it entails and characterizes the equilibrium outcome when both moral-hazard

\footnotetext{
${ }^{7}$ Leland and Pyle (1977) is the first application of signaling in finance; they show how a risk-averse owner can signal the underlying quality of its firm in an initial public offering (IPO) by retaining a substantial undiversified stake in the firm. Bhattacharya (1979) investigate signaling through dividends. Myers and Majluf (1984) show that, when the firm has private information about the value of its assets, the decision to rise new capital can be used as a signaling devise. Among others, Besanko and Thakor (1987), Bester (1985) and (1987), Chan and Kanatas (1985) study the possibility of signaling by pledging collateral. In Diamond (1991), a borrower enters into a short-term borrowing contract in order to signal her creditworthiness. Welch (1989), Allen and Faulhaber (1989) have extended the Leland and Pyle's theory by modeling low IPO price as a signal of the quality of the undertaken project.
} 
and adverse selection have bite. Subsection 4.2 deals with uniqueness and investigates efficiency. The paper's Conclusion follows.

\section{Model Set-up}

The model is borrowed from Tirole (2006) and has been illustrated in Barigozzi and Tedeschi (2015). Here we briefly present the model's setup and refer the reader to the mentioned paper for a detailed discussion of the assumptions about motivated borrowers, ethical banks and ethical projects and for some real world examples.

We consider a credit market with a large number of both risk-neutral borrowers (she) and banks (it). Borrowers undertake a project that requires an investment. Each borrower can apply for at most one loan, and different types of projects exist. We call $I^{k}$ the endogenous amount of the investment, where $k \in\{0,1\}$ indicates the type of project. When $k=1$ the project is "ethical", and when $k=0$ the project is "non-ethical" or standard. The difference between the two projects is specified below.

All the borrowers own the same asset $A$. The borrowers do not have sufficient capital and/or collateral no matter which project they are interested in, and hence need to borrow $I^{k}-A$. If the project is undertaken, it generates a cash flow per unit of investment, which is $R^{k}>0$ if successful and zero in the case of failure. ${ }^{8}$ The total cash flow if the project is successful is $R^{k} \cdot I^{k} \geq 0$.

Ethical projects represent all projects leading to social benefits beyond profits (for example, projects that improve communities and have a positive impact on the environment). The profitability of ethical projects is on average lower than that of standard ones. In particular, standard projects have a higher return in the event of success, that is: $R^{0} \geq R^{1}>0$. Both types of projects are perfectly observable and have independent distributions.

To summarize, two sectors exist in the credit market: the market for ethical projects and the market for standard ones. The latter assures higher expected returns to investors.

All projects are subject to moral hazard: entrepreneurs can behave or misbehave. If they behave, the probability of success is $p_{H}$; otherwise it is $p_{L}$, with $p_{H}>p_{L}$. We define $\Delta_{p} \equiv p_{H}-p_{L}$. An entrepreneur who misbehaves will enjoy a private benefit whose value is $P \cdot I$. Otherwise, the private benefit will be nought. We call $a \in\{0,1\}$ the behavior of the entrepreneur. In particular, $a=0$ if the entrepreneur misbehaves, while $a=1$ if she behaves. Thus, $p(1)=p_{H}$ and $p(0)=p_{L}$, respectively. The borrowers are protected by limited liability: hence their income cannot be negative. Given limited liability, the moral hazard problem is relevant even though both agents are risk neutral.

There are also two types of banks and entrepreneurs, respectively denoted as $i \in\{0,1\}$ and $j \in\{0,1\}$. For both lenders and borrowers type 0 denotes the standard agents, whereas type 1 indicates socially responsible agents.

In case of success, revenues are shared between lenders and borrowers: $L_{i j}^{k}$ and $B_{i j}^{k}$ are, respectively,

\footnotetext{
${ }^{8}$ This is without generality loss because we proved that the optimal contract is a debt one.
} 
the incomes of a lender of type $i$ and that of a borrower of type $j$ when trading with each other, if the investment is of type $k$, hence obtaining: $L_{i j}^{k}+B_{i j}^{k}=R^{k} \cdot I$.

In the following sections, we characterize the optimal contracts $\left(B_{i j}^{k}, I_{i j}^{k}\right)$ that specify the type of project, the amount invested, and how revenues are shared between lenders and borrowers in the case of success given the type of agents trading together.

The crucial ingredients of our model are the premium for social responsibility $\theta$ and the premium for successful interaction $\Delta_{\theta}$. The premium for social responsibility is a non-pecuniary benefit with monetary value $\theta$ that a motivated borrower obtains when undertaking an ethical project, no matter the project's outcome and whatever the type of lender. The additional premium for successful interaction $\Delta_{\theta}$ is the extra premium of social responsibility accrued by a motivated agent when implementing an ethical project financed by an ethical bank. In fact, the motivated borrower anticipates that, if the ethical bank makes profits, given its commitment to investing in ethical projects, it will use the liquidity to finance other social and solidarity-based projects, increasing expected utility of the motivated borrower.

The entrepreneurs' payoff can be written as:

$$
U_{i j}^{k}=p(a)\left(B_{i j}^{k}+i j k \Delta_{\theta}\right)+j k \theta-A+(1-a) P I_{i j}^{k}
$$

Note that the premium for social responsibility $\theta$ is positive only if a motivated borrower invests in an ethical project $(j=k=1)$, whereas the premium for successful interaction $\Delta_{\theta}$ is positive only if a motivated borrower invests in an ethical project with an ethical bank $(i=j=k=1)$ and the project succeeds.

Standard lenders maximize their profits. When the moral hazard problem is taken care of, expected profits become:

$$
p_{H} L_{0 j}^{k}-I_{0 j}^{k}+A
$$

We assume that ethical banks maximize expected profits $^{9}$, as do standard lenders, but commit to investing only in ethical projects (therefore $k=1$ ). Because ethical projects have a lower profitability than standard ones, commitment to ethical projects implies that ethical banks are sacrificing profits for the social interest. ${ }^{10}$ Subscript $j$ in (3) indicates that both standard and motivated borrowers can invest with ethical banks:

$$
p_{H} L_{1 j}^{1}-I_{1 j}^{1}+A
$$

As already mentioned, borrowers are endowed with all the bargaining power and propose a contract to lenders so that the banks' expected profits are zero at the equilibrium. ${ }^{11}$ The sequence of actions is thus as follows: the borrower offers the contract, then the lender accepts or refuses the proposal. Subsequently, the borrower decides whether to behave or misbehave, uncertainty concerning the project is solved, and the contract is implemented.

\footnotetext{
${ }^{9}$ One can show that nothing changes when assuming that ethical banks maximize total revenue from ethical projects.

${ }^{10}$ Commitment to ethical projects is possible because borrowers have all the market power and propose contracts, in the form of a specific and observable project for funding, to banks which can accept or reject them.

${ }^{11}$ This is equivalent to assuming Bertrand competition among lenders.
} 


\section{Second-best: Loan Agreements under Moral Hazard}

The setting with moral hazard only is investigated in Barigozzi and Tedeschi (2015). Here we summarize their main results because they represent the starting point of the analysis of moral hazard and adverse selection which is the focus of the present paper.

Assume that the project and the borrower type are common knowledge, while borrowers have private information on their behavior, which may or may not increase the probability of success of the project. The optimal contract hence maximizes the borrower's utility under the borrower's incentive compatibility constraint $\left(I C_{i j}^{B k}\right)$ and the lenders' participation constraint $\left(I R_{i j}^{L k}\right)$ (see Appendix 6.1).

One can show that standard borrowers optimally sign a contract with a standard bank for a standard project. Motivated borrowers, instead, at equilibrium can either sign the same contract (because all borrowers are the same when investing in standard projects) or they can invest in an ethical project with an ethical bank. The third option of motivated borrowers, i.e. investing in an ethical project with a standard bank, is discarded because always dominated. In fact, when trading with an ethical bank, motivated borrowers may also receive the premium for successful interaction, $\Delta_{\theta}$. Moreover, the matching of motivated borrowers with ethical lenders reduces the frictions caused by the agency issue, as we briefly explain below, allowing for the possibility of better contract conditions, and this despite the lower profitability of ethical projects.

To see why ethical banks are more efficient than standard lenders in solving the moral hazard problem of the motivated borrower, let us consider the incentive compatibility constraint of a motivated borrower trading with an ethical bank:

$$
B_{11}^{1}+\Delta_{\theta} \geq \frac{P I_{11}^{1}}{\Delta_{p}}
$$

The left-hand side of the incentive compatibility constraint includes all the gains obtained by the borrower when a project is successful: an increase in revenues, $B_{11}^{1}$, and an increase in psychological well-being, $\Delta_{\theta}$. The latter is what makes the incentive compatibility constraint in such a case distinctive, in fact this term appears neither in the incentive compatibility constraint of a standard borrower nor in the incentive compatibility constraint of a motivated borrower when investing in an ethical project with a standard bank. Hence, we conclude that the matching of motivated borrowers and ethical lenders relaxes the incentive constraint of the borrowers.

The market structure at equilibrium depends on the motivated borrower's choice of investing in a standard project with a standard bank or of investing in an ethical project with an ethical bank. The following proposition from Barigozzi and Tedeschi (2015) describes the equilibrium in the credit market under moral hazard. The analytical expressions for the terms appearing in the two optimal contracts $\left(B_{00}^{0 *}, I_{00}^{0 *}\right)$ and $\left(B_{11}^{1 *}, I_{11}^{1 *}\right)$ and the three threshold values $\bar{\Delta}_{\theta}, \underline{\Delta}_{\theta}$ and $\triangleq_{\theta}$ for the premium for successful interactions are illustrated in Appendix 6.1.

Proposition 1 Second-best (From Barigozzi and Tedeschi 2015). When moral hazard is the unique asymmetric information characterizing the credit market, three threshold values for the premium for 
successful interactions, $\bar{\Delta}_{\theta}>\underline{\Delta}_{\theta} \geq \underline{\underline{\Delta}}_{\theta} \geq 0$, exist such that:

- when $\Delta_{\theta} \geq \triangleq_{\theta}$, then the credit market is fully segmented and contracts $\left(B_{00}^{0 *}, I_{00}^{0 *}\right)$ and $\left(B_{11}^{1 *}, I_{11}^{1 *}\right)$ are signed by standard and motivated borrowers respectively.

1. If $\Delta_{\theta} \geq \bar{\Delta}_{\theta}$, the contracts are such that $I_{11}^{1 *}>I_{00}^{0 *}$ and $B_{11}^{1 *}>B_{00}^{0 *}$.

2. If $\underline{\Delta}_{\theta} \leq \Delta_{\theta} \leq \bar{\Delta}_{\theta}$, the contracts are such that: $I_{11}^{1 *}>I_{00}^{0 *}$ and $B_{11}^{1 *}<B_{00}^{0 *}$.

3. If $\underline{\underline{\Delta}}_{\theta}<\Delta_{\theta} \leq \underline{\Delta}_{\theta}$, the contracts are such that: $I_{11}^{1 *}<I_{00}^{0 *}$ and $B_{11}^{1 *}<B_{00}^{0 *}$.

- When $0 \leq \Delta_{\theta}<\triangleq_{\theta}$, then ethical banks are not active and there is no market for ethical projects: all borrowers invest in standard projects and choose the contract $\left(B_{00}^{0 *}, I_{00}^{0 *}\right)$.

To sum up, only socially motivated borrowers potentially engage in ethical projects. If they do not, then ethical banks cannot operate, and the market for ethical projects does not exist. If, instead, motivated borrowers undertake ethical projects, then ethical banks are active and the market is fully segmented. That is, standard agents trade among themselves in the market for standard projects while ethical banks trade with motivated borrowers in the market for ethical projects. This occurs when the premium for successful interaction is sufficiently high $\left(\Delta_{\theta} \geq \underline{\underline{\Delta}}_{\theta}\right)$. For larger values of the successful interaction premium $\left(\Delta_{\theta} \geq \underline{\Delta}_{\theta}\right)$, not only are ethical banks active, but they even provide greater funding to motivated borrowers than what is received by standard borrowers from standard banks. Finally, when the premium increases even further $\left(\Delta_{\theta} \geq \bar{\Delta}_{\theta}\right)$, ethical banks surprisingly guarantee greater revenue to motivated borrowers than what standard borrowers can obtain. In the latter scenario, motivated borrowers trading with ethical banks unambiguously receive better contract conditions.

\section{Third-best: Loan Agreements under Moral Hazard and Ad- verse Selection}

Now lenders cannot observe neither the borrowers' behavior nor their motivation, whereas lenders' CSR is still common knowledge, together with the fraction of motivated borrowers in the credit market $(q)$. As already mentioned, this setting fits a situation where lenders are banks with well known characteristics, while borrowers are new firms without reputation. As illustrated in Proposition 1, this environment is interesting since, when the premium for successful interaction is sufficiently high, motivated borrowers trading with ethical banks obtain better contract conditions than standard borrowers trading with standard lenders. Thus, standard borrowers could take advantage of their private information by investing in ethical projects and pretending to be motivated. In this latter case ethical banks may obtain negative profits, since standard borrowers mimicking motivated ones possibly misbehave. In different words, the second-best contract for motivated borrowers, $\left(B_{11}^{1 *}, I_{11}^{1 *}\right)$, is not necessarily incentive compatible for 
standard borrowers. In the following, we study the third-best of the model, i.e. we derive the separating allocation allowing to distinguish different borrowers, we study the distortion it entails and prove uniqueness of the equilibrium outcome. ${ }^{12}$

\subsection{The RSW allocation with market segmentation}

Recall that borrowers have all the market power and propose contracts to banks. Since borrowers are the informed party, we are considering here a case of contract design by an informed principal and the equilibrium concept is Perfect Bayesian Equilibrium. The seminal paper on this topic is Maskin and Tirole (1992), whose results have been adapted to the case of competition in a credit market with two types of borrowers and homogeneous lenders in Section 6.4 of Tirole (2006). In that model two types of informed borrowers and many homogeneous lenders interact in the market. As mentioned in the Introduction, the RSW allocation corresponds to the separating allocation entailing the lowest cost of separation when two self-selecting contracts that are profitable type-by-type are offered. Moreover, if the RSW allocation is interim efficient (i.e. it is profitable also in expectation) with respect to the lenders' priors, then it is the unique Perfect Bayesian equilibrium of the game (the formal result is stated in Corollary to Theorem 1 in Maskin and Tirole 1992).

We depart from Section 6.4 of Tirole (2006) for two reasons: first, in our setting moral-hazard is also an issue, second and more importantly for what follows, we are considering a credit market with heterogeneous borrowers and heterogeneous lenders. This implies that two menus (one for each type of lenders) will be offered in equilibrium.

The three-stage timing of actions is adapted to our setting with heterogeneous agents and is the following. In the first stage, borrowers design a menu for standard lenders and a menu for ethical lenders and offer the menus to lenders. Each menu contains three contracts at most: the null contract together with either two separating contracts (one for each type of borrowers) or a pooling contract. In the second stage, lenders accept the offer if they earn nonnegative expected profits from the contracts appearing in the menu designed for them. ${ }^{13}$ In the third stage, each borrower picks one contract from each menu: the contract overall preferred among all contracts appearing in the two menus and the null contract from the dominated menu. Then borrowers decide whether to behave or misbehave. Finally, uncertainty concerning the project is solved, and the contract is executed.

It is important to stress that each menu must be complete in the sense that it must contain (selfselecting) contracts for the two types of borrowers, contingent on the specific type of lender. In the second stage lenders accept the menu designed for them if, given their beliefs on the borrowers' type, their expected profits will be non-negative. The null contract appears in each menu so that each type of

\footnotetext{
${ }^{12} \mathrm{We}$ will distinguish between the equilibrium menus offered to ethical and standard banks and the equilibrium outcome/allocation. We will prove that the menu offered in equilibrium to ethical banks is not unique whereas the equilibrium outcome is unique.

${ }^{13}$ Recall that standard lenders optimally fund standard projects because social responsibility of motivated borrowers does not affect the borrowers' incentive constraint. Ethical banks, instead, commit to fund only ethical projects.
} 
borrower is able to trade with just one type of lender and market segmentation can occur.

Before proceeding, the following clarifications are useful. When dealing with ethical lenders we are considering a setting with common values. In fact, the borrower's type affects the expected payoff of the ethical bank throughout the incentive compatibility constraint of the borrower that is type dependent (see constraint $I C_{11}^{B}$ in the previous Section). In addition, if the incentive constraint is not satisfied, then the borrower misbehaves and the ethical lender's expected profits become negative. On the contrary, the type of the borrower does not affect the expected payoff of commercial banks so that the setting is about private values for those lenders.

To solve the contract proposal game we proceed as follows. We show that, in third-best, the secondbest contracts are incentive compatible and thus are still offered when $\Delta_{\theta}<\bar{\Delta}_{\theta}$. We then turn to the case where $\Delta_{\theta} \geq \bar{\Delta}_{\theta}$ and we observe that the second-best contract $\left(B_{00}^{0 *}, I_{00}^{0 *}\right)$ is the (pooling) contract characterizing the menu offered to standard banks. Then, we derive the menu of contracts that borrowers offer to ethical lenders. To do so, we first define the RSW allocation ignoring market segmentation. Subsequently, we define the RSW allocation with market segmentation and we show that the latter dominates the former. ${ }^{14}$ This allows us to conclude that the RSW allocation with market segmentation is the allocation which characterizes the menu offered to ethical lenders. The equilibrium outcome will be given by the contracts selected by the two types of borrowers among the contracts appearing in the two equilibrium menus.

When borrowers trade with standard lenders, separation has no meaning because all borrowers are the same. Moreover, borrowers optimally offer the second-best contract $\left(B_{00}^{0 *}, I_{00}^{0 *}\right)$ :

Remark 1 In third-best, $(i)$ borrowers offer to standard lenders a menu with the second-best (pooling) contract and the null contract: $\left\{\left(B_{00}^{0 *}, I_{00}^{0 *}\right),(0,0)\right\}$. (ii) In equilibrium, both borrowers' types can always guarantee themselves the payoff associated with the second-best contract $\left(B_{00}^{0 *}, I_{00}^{0 *}\right)$.

From the previous Remark and from Proposition 1, it straightforwardly follows that, when $\Delta_{\theta}<\triangleq_{\theta}$, borrowers propose contract $\left(B_{00}^{0 *}, I_{00}^{0 *}\right)$ to standard lenders, and no separation is possible because ethical banks are not active.

When instead, for $\Delta_{\theta} \geq \triangleq_{\theta}$, borrowers are confronted with ethical and standard banks, separation with market segmentation is possible if the self-selection constraints of the two types of borrowers are satisfied. Obviously, if second-best contracts $\left(B_{00}^{0 *}, I_{00}^{0 *}\right)$ and $\left(B_{11}^{1 *}, I_{11}^{1 *}\right)$ verify such constraints, then those contracts will be proposed in third-best as well.

From Proposition 1 we know that motivated borrowers prefer contract $\left(B_{11}^{1 *}, I_{11}^{1 *}\right)$ to contract $\left(B_{00}^{0 *}\right.$, $\left.I_{00}^{0 *}\right)$ when $\Delta_{\theta} \geq \triangleq_{\theta}$, so that contract $\left(B_{00}^{0 *}, I_{00}^{0 *}\right)$ is envy free. Moreover, standard borrowers prefer contract

\footnotetext{
${ }^{14} \mathrm{As}$ it will be clarified below, in the RSW allocation with market segmentation, borrowers take into account that trading with standard lenders represents an outside-option which relaxes the self-selection constraint preventing standard borrowers from mimicking motivated entrepreneurs.
} 
$\left(B_{00}^{0 *}, I_{00}^{0 *}\right)$ to contract $\left(B_{11}^{1 *}, I_{11}^{1 *}\right)$ when $\Delta_{\theta}<\bar{\Delta}_{\theta}$ since, with the former, they receive a higher expected utility than with the latter. In fact, for $\Delta_{\theta} \leq \bar{\Delta}_{\theta}, B_{00}^{0 *}>B_{11}^{1 *}$ holds so that:

$$
p_{H} B_{00}^{0 *}-A>p_{H} B_{11}^{1 *}-A .
$$

The previous reasoning implies that, when $\triangleq_{\theta} \leq \Delta_{\theta}<\bar{\Delta}_{\theta}$, the credit market is fully segmented and the second-best contracts $\left(B_{00}^{0 *}, I_{00}^{0 *}\right)$ and $\left(B_{11}^{1 *}, I_{11}^{1 *}\right)$ satisfy the borrowers' self-selection constraints. Here, the separation of borrowers' types occurs without additional agency costs, i.e. the unique friction is the one caused by moral hazard.

Remark 2 In third-best, when $\Delta_{\theta}<\bar{\Delta}_{\theta}$, the second-best allocation illustrated in Proposition 1 is still optimal and is implemented through the two menus: $\left\{\left(B_{10}^{1 *}, I_{10}^{1 *}\right),\left(B_{11}^{1 *}, I_{11}^{1 *}\right),(0,0)\right\}$ for ethical banks and $\left\{\left(B_{00}^{0 *}, I_{00}^{0 *}\right),(0,0)\right\}$ for standard banks, where $\left(B_{10}^{1 *}, I_{10}^{1 *}\right)$ is the best contract that standard borrowers can offer to ethical banks. ${ }^{15}$.

In the third stage, when borrowers choose a contract from each menu, motivated borrowers pick $\left(B_{11}^{1 *}, I_{11}^{1 *}\right)$ from the menu for ethical banks and the null contract from the other one; standard borrowers pick $\left(B_{00}^{0 *}, I_{00}^{0 *}\right)$ from the menu for standard banks and the null contract from the other one. Interestingly, the menu for ethical banks contains a latent contract, $\left(B_{10}^{1 *}, I_{10}^{1 *}\right)$, that will never be chosen in equilibrium because it is dominated by $\left(B_{00}^{0 *}, I_{00}^{0 *}\right)$.

We consider now the most interesting case where $\Delta_{\theta} \geq \bar{\Delta}_{\theta}$ and the opposite of inequality (4) holds because $B_{00}^{0 *}<B_{11}^{1 *}$. Now both borrowers' types prefer contract $\left(B_{11}^{1 *}, I_{11}^{1 *}\right)$ so that adverse selection has bite and the standard borrowers are the "bad" types who can take advantage of their private information.

Below we describe the RSW allocation with homogeneous agents (See Tirole 2006, section 6.4) in our setting. It corresponds to the separating contracts appearing in the menu that borrowers offer to ethical banks when they ignore that the pooling contract $\left(B_{00}^{0 *}, I_{00}^{0 *}\right)$ offered in the menu designed for standard banks is the best available option for standard borrowers.

Definition 1 The $\boldsymbol{R} \boldsymbol{S} \boldsymbol{W}$ allocation with homogeneous lenders corresponds to the separating contracts $\left(B_{10}^{1 *}, I_{10}^{1 *}\right)$ and $\left(\hat{B}_{11}^{1}, \hat{I}_{11}^{1}\right)$ which do not take into account the menu offered to standard lenders.

${ }^{15}$ The analytical expression for $B_{10}^{1 *}$ is the following:

$$
B_{10}^{1 *}=\frac{P}{\Delta_{p}} \frac{A}{1-p_{H}\left(R^{1}-\frac{P}{\Delta_{p}}\right)}<B_{00}^{0 *}
$$

and is obtained solving the program of a standard borrower contracting for an ethical project with an ethical bank. It corresponds to program (8) in Appendix 6.1 with $R^{1}$ replacing $R^{0}$. Obviously, contract $\left(B_{10}^{1 *}, I_{10}^{1 *}\right)$ is dominated by $\left(B_{00}^{0 *}\right.$, $\left.I_{00}^{0 *}\right)$ because of standard projects' higher returns. 
Contract $\left(\hat{B}_{11}^{1}, \hat{I}_{11}^{1}\right)$ solves the following program:

$$
\begin{array}{ccc}
\max _{B_{11}^{1}, I_{11}^{1}} & p_{H} B_{11}^{1}+p_{H} \Delta_{\theta}+\theta-A & \\
\text { s.t. } & B_{11}^{1}+\Delta_{\theta} \geq \frac{P}{\Delta_{p}} I_{11}^{1} & \left(I C_{11}^{B}\right) \\
& \left(p_{H} R^{1}-1\right) I_{11}^{1}-p_{H} B_{11}^{1}+A \geq 0 & \left(I R_{11}^{L}\right) \\
& p_{H} B_{10}^{1 *} \geq p_{L} B_{11}^{1}+P I_{11}^{1} & \left(S S_{0 / 1}^{\text {hom }}\right)
\end{array}
$$

where the incentive constraint of motivated borrowers $\left(I C_{11}^{B}\right)$ is satisfied, together with the participation constraint of ethical banks $\left(I R_{11}^{L}\right)$ and where $B_{10}^{1 *}$, appearing in the standard borrowers' self-selection constraint $\left(S S_{0 / 1}^{\text {hom }}\right)$, is the best contract that standard borrowers can offer to ethical banks.

Notice that, in the right-hand side of the self-selection constraint $\left(S S_{0 / 1}^{\text {hom }}\right)$, standard borrowers mimicking motivated ones misbehave ( $a=0$ so that the probability of a successful investment is just $\left.p_{L}\right)$. Indeed, when standard borrowers pick the contract designed for motivated types, their incentive constraint is not necessarily satisfied because they do not receive the premium for successful interaction $\Delta_{\theta}$. The RSW allocation ignoring market segmentation assures that standard borrowers prefer contract $\left(B_{10}^{1 *}, I_{10}^{1 *}\right)$ to $\left(\hat{B}_{11}^{1}, \hat{I}_{11}^{1}\right)$ when, by picking $\left(\hat{B}_{11}^{1}, \hat{I}_{11}^{1}\right)$, they misbehaves (that is when $\left(\hat{B}_{11}^{1}, \hat{I}_{11}^{1}\right)$ provides the highest payoff to standard borrowers). Also note that the Weak Monotonic Profit assumption (see Tirole 2006 , page 267), requiring that contract $\left(B_{10}^{1 *}, I_{10}^{1 *}\right)$ is profitable also when signed by the "good" (ethical) borrowers, is trivially verified in our setting.

In Maskin and Tirole (1992) and Tirole (2006, section 6.4), borrowers can obtain at least the payoff associated with a RSW allocation equivalent to the one described above. Conversely, in our setting with heterogeneous banks, we stated in Remark 1 that borrowers can always obtain the payoff associated with $\left(B_{00}^{0 *}, I_{00}^{0 *}\right)$. The latter contract dominates $\left(B_{10}^{1 *}, I_{10}^{1 *}\right)$ for standard borrowers, because standard projects have higher expected returns than ethical ones. Clearly, then, separating contracts that dominate the RSW allocation defined above and that are still profitable type-by-type do exist.

Let us now define the RSW allocation with market segmentation.

Definition 2 The $R \boldsymbol{S} W$ allocation with market segmentation corresponds to the separating allocation $\left(B_{10}^{1 *}, I_{10}^{1 *}\right)$ and $\left(B_{11}^{1 * *}, I_{11}^{1 * *}\right)$ such that motivated borrowers anticipate that trading with standard banks is the best-option of standard borrowers. Contract $\left(B_{11}^{1 * *}, I_{11}^{1 * *}\right)$ solves the following program:

$$
\begin{array}{ccc}
\max _{B_{11}^{1}, I_{11}^{1}} & p_{H} B_{11}^{1}+p_{H} \Delta_{\theta}+\theta-A & \\
\text { s.t. } & B_{11}^{1}+\Delta_{\theta} \geq \frac{P}{\Delta_{p}} I_{11}^{1} & \left(I C_{11}^{B}\right) \\
& \left(p_{H} R^{1}-1\right) I_{11}^{1}-p_{H} B_{11}^{1}+A \geq 0 & \left(I R_{11}^{L}\right) \\
& p_{H} B_{00}^{0 *} \geq p_{L} B_{11}^{1}+P I_{11}^{1} & \left(S S_{0 / 1}^{\text {het }}\right)
\end{array}
$$

(RSW het)

where the incentive constraint of the motivated borrowers $\left(I C_{11}^{B}\right)$ is satisfied, together with the participation constraint of ethical banks $\left(I R_{11}^{L}\right)$, and where $B_{00}^{0 *}$, appearing in the standard borrowers' self-selection 
constraint $\left(S S_{0 / 1}^{h e t}\right)$, is the expected payment that standard borrowers propose to standard banks in the second-best contract. Again, $\left(B_{10}^{1 *}, I_{10}^{1 *}\right)$ is the best contract that standard borrowers can offer to ethical banks.

Being $B_{00}^{0 *}>B_{10}^{1 *}$, the self-selection constraint $\left(S S_{0 / 1}^{h e t}\right)$ is easier to satisfy than $\left(S S_{0 / 1}^{\text {hom }}\right)$. Then, contract $\left(B_{11}^{1 * *}, I_{11}^{1 * *}\right)$ assures to motivated borrowers a higher payoff than $\left(\hat{B}_{11}^{1}, \hat{I}_{11}^{1}\right)$ because it is derived from a less-constrained program. In different words: the RSW allocation with market segmentation strictly dominates the RSW allocation of Definition $1 .^{16}$

Importantly, borrowers anticipate here that the best available option for standard borrowers is contract $\left(B_{00}^{0 *}, I_{00}^{0 *}\right)$ and that the contract targeted to standard borrowers and appearing in the menu for ethical banks will never be chosen in equilibrium (recall that any contract signed by ethical banks and standard borrowers necessarily accrues lower profits than $\left(B_{00}^{0 *}, I_{00}^{0 *}\right)$ to the latter). Nevertheless, notice once again that the menu offered to ethical banks must be complete (that is, it must contain the null contract and self-selecting contracts for the two types of borrowers) and feasible for the bank (that is, the bank must earn nonnegative expected profits from the menu), otherwise the bank will not accept the menu in the second stage. Indeed, we could substitute $\left(B_{10}^{1 *}, I_{10}^{1 *}\right)$ with any other contract that signed by standard or by motivated borrowers assures non-negative profits to ethical banks.

We are now able to describe the equilibrium with market segmentation assuring the lowest payoff to the borrowers. Suppose that, in the first stage, borrowers offer the menu $\left\{\left(B_{10}^{1 *}, I_{10}^{1 *}\right),\left(B_{11}^{1 * *}, I_{11}^{1 * *}\right),(0,0)\right\}$ to ethical banks and the menu $\left\{\left(B_{00}^{0 *}, I_{00}^{0 *}\right),(0,0)\right\}$ to standard lenders. In the second stage, each type of lender will accept the offer because the menus contain contracts that are feasible (type-by-type) and thus assure non-negative profits to the targeted bank, no matter the bank's beliefs about borrowers' types. In the third stage, borrowers will pick their preferred contract from each menu: standard borrowers will chose $\left(B_{00}^{0 *}, I_{00}^{0 *}\right)$, while motivated ones will choose $\left(B_{11}^{1 * *}, I_{11}^{1 * *}\right)$. Hence, we derived the lower bound for the payoff that borrowers can reach in equilibrium in our setting with heterogeneous lenders (see Proposition 5 of Maskin and Tirole 1992). To sum up:

Lemma 1 (i) The $R S W$ allocation which takes into account market segmentation strictly dominates the $R S W$ allocation that ignores market segmentation. (ii) The equilibrium outcome is such that standard borrowers sign the second-best contract $\left(B_{00}^{0 *}, I_{00}^{0 *}\right)$ with standard banks, whereas motivated borrowers sign with ethical banks the third-best contract $\left(B_{11}^{1 * *}, I_{11}^{1 * *}\right)$. Such equilibrium outcome guarantees the lowest payoff that both borrowers can reach in the credit market with standard and ethical banks.

Again, notice that the menu offered to ethical banks in equilibrium is not unique because of the latent contract $\left(B_{10}^{1 *}, I_{10}^{1 *}\right)$. As mentioned before, the latter can be substituted with any other contract that signed by standard or by motivated borrowers assures non-negative profits to ethical banks.

\footnotetext{
${ }^{16}$ In the end of Appendix 6.3, we also show that the RSW allocation in Definition 2 is Pareto superior to the allocation derived from a program similar to RSW het but where the standard borrowers' incentive constraint is satisfied so that standard borrowers behave in $\left(S S_{0 / 1}^{h e t}\right)$.
} 
In the following lemma we characterize contract $\left(B_{11}^{1 * *}, I_{11}^{1 * *}\right)$ belonging to the equilibrium allocation with market segmentation:

Lemma 2 The third-best contract $\left(B_{11}^{1 * *}, I_{11}^{1 * *}\right)$ is such that $B_{11}^{1 *}>B_{00}^{0 *}>B_{11}^{1 * *}$ and $I_{11}^{1 *}>I_{11}^{1 * *}>I_{00}^{0 *}$.

Proof. See the Appendix 6.3.

Hence, when $\Delta_{\theta} \geq \bar{\Delta}_{\theta}$, the "good" borrowers must pay the cost of separating from the "bad" borrowers and sign a contract which is worse than the second-best one because it entails a lower expected payment and a lower investment. We will comment on the properties of the equilibrium outcome after Proposition 3 in the following Section.

\subsection{Uniqueness and efficiency}

From Corollary to Proposition 3 of Maskin and Tirole (1992), we know that the RSW allocation (with homogeneous agents) is interim efficient for a non-empty set of beliefs. From the Corollary to Theorem 1 we also know that, if the RSW allocation is interim efficient, then it is the unique equilibrium. If it is not, then a multiplicity of equilibria exists in the form of a continuum of Pareto superior separating allocations with cross-subsidies.

Importantly, as we will explain, cross-subsidies between different menus are not feasible in our setting so that we are able to show some interesting new result about uniqueness. We first prove that the allocation with market segmentation given by $\left(B_{11}^{1 * *}, I_{11}^{1 * *}\right)$ and $\left(B_{00}^{0 *}, I_{00}^{0 *}\right)$ is the unique equilibrium outcome of the contract proposal game. Then we derive conditions assuring that, given the banks' priors $(q, 1-q)$, the equilibrium allocation with market segmentation is also interim efficient.

In our setting we must distinguish between interim efficiency when considering cross-subsidies between contracts offered to ethical and to standard banks and when considering cross-subsidies between contracts offered to ethical bank only. We thus define:

Definition 3 Interim Efficiency. (i) The equilibrium allocation with market segmentation is Unconstrained Interim Efficient if no separating contracts profitable in expectation exist that are preferred by both borrowers' types when cross subsidies between ethical and standard banks are considered. (ii) The equilibrium allocation with market segmentation is Constrained Interim Efficient if no separating contracts profitable in expectation exist that are preferred by both borrowers' types when only cross subsidies between contracts financed by ethical banks are considered.

Notice that Unconstrained Interim Efficiency is a more demanding criterion than Constrained Interim Efficiency. Intuitively, a larger set of allocations that break-even in expectation is available when crosssubsidies between ethical and standard banks are possible than when only cross-subsidies inside ethical banks are admitted. ${ }^{17}$

\footnotetext{
${ }^{17}$ Uniqueness follows from the observation below. An equilibrium allocation must be incentive compatible and, from Corollary 1 (part $(i i))$, must weakly Pareto-dominate the equilibrium allocation given by $\left(B_{11}^{1 * *}, I_{11}^{1 * *}\right)$ and $\left(B_{00}^{0 *}, I_{00}^{0 *}\right)$.
} 
Because, in the second stage, banks only accept menus that guarantee nonnegative expected profits, we state that:

Remark 3 In third-best, at the equilibrium, only cross-subsidies between contracts offered in the menu designed for ethical banks are possible.

In fact, in the case where cross-subsidies among banks were implemented, the menu designed for standard banks would contain a pooling contract that leads to negative profits to be covered with positive profits earned by ethical banks in the other menu. But the menu for standard lenders would not be accepted in the second stage of the Contract Proposal Game. We conclude that each menu must be feasible (in isolation) for the banks.

Below we show that, in the menu offered to ethical banks, feasible contracts with cross-subsidies that Pareto-dominate the allocation with market segmentation do not exist.

Proposition 2 Uniqueness. (i) The equilibrium allocation with market segmentation is always Constrained Interim Efficient. (ii) The equilibrium allocation with market segmentation is unique.

Proof. (i) See the Appendix 6.4. (ii) It directly follows from (i).

In order to verify whether Pareto dominating contracts with cross-subsidies financed by ethical banks exist (point $(i)$ ), we must consider two programs with ethical bank as the lender. In the first program (see Program 15 in Appendix 2) we derive the expected profits of the ethical bank when it signs a contract with the standard borrower which entails the second-best expected profits, $p_{H} B_{00}^{0 *}$, plus a transfer $T$ (the latter assures that the contract is Pareto improving for standard borrowers). From such a contract the ethical bank earns negative profits which must be financed by a profitable contract $\left(B_{11}^{1^{\circ}}, I_{11}^{1^{\circ}}\right)$ that motivated borrowers prefer to $\left(B_{11}^{1 * *}, I_{11}^{1 * *}\right)$. Thus, in the second step, we verify whether the Pareto improving new contract $\left(B_{11}^{1^{\circ}}, I_{11}^{1^{\circ}}\right)$ is profitable enough to cover the loss on bad borrowers (see Program 17 in Appendix 2). Intuitively Pareto-improving contracts do not exist because, given the lower expected return of ethical projects, meeting expected profits $p_{H} B_{00}^{0 *}$ is too costly for the ethical bank.

The equilibrium allocation with market segmentation is characterized in the Proposition below which incorporates results from Remark 2 and Lemma 2.

Proposition 3 Third-best. Considering the threshold values $\bar{\Delta}_{\theta}>\underline{\Delta}_{\theta} \geq \triangleq_{\theta} \geq 0$,

- when $\Delta_{\theta} \geq \bar{\Delta}_{\theta}$, standard borrowers sign the second-best contract $\left(B_{00}^{0 *}, I_{00}^{0 *}\right)$ with standard lenders. Motivated borrowers sign with ethical banks the third-best contract $\left(B_{11}^{1 * *}, I_{11}^{1 * *}\right)$ which is characterized by lower revenue and investment than their second-best contract, but higher investment than the second-best contract of standard borrowers. The credit market is fully segmented.

However, it cannot strictly Pareto-dominate such allocation if the latter is interim efficient and so it must yield the same payoffs to the borrowers in this case. 
- When $\triangleq_{\theta} \leq \Delta_{\theta} \leq \bar{\Delta}_{\theta}$, standard borrowers sign the second-best contract $\left(B_{00}^{0 *}, I_{00}^{0 *}\right)$ with standard lenders. Motivated borrowers sign the second-best contract $\left(B_{11}^{1 *}, I_{11}^{1 *}\right)$ with ethical banks. The credit market is fully segmented.

- When $\Delta_{\theta}<\triangleq_{\theta}$, then both borrowers' types sign the second-best contract $\left(B_{00}^{0 *}, I_{00}^{0 *}\right)$ with standard banks. Ethical banks are not active and the market for ethical projects does not exist.

When $\Delta_{\theta}<\underline{\underline{\Delta}}_{\theta}$, neither the market for ethical projects nor ethical banks exist because all borrowers invest in standard projects. Whereas, for $\Delta_{\theta} \geq \triangleq_{\theta}$, ethical banks are active and the market is fully segmented as in the second-best. More specifically, when $\triangleq_{\theta} \leq \Delta_{\theta}<\bar{\Delta}_{\theta}$, the second-best contracts are envy free. Instead, when $\Delta_{\theta} \geq \bar{\Delta}_{\theta}$, standard borrowers are willing to mimic motivated ones to receive better loan conditions and the menu that borrowers offer to ethical banks must satisfy the selfselecting constraint of standard borrowers. As a result, motivated borrowers pay the cost of separation and sign with ethical banks a contract entailing a higher investment $\left(I_{00}^{0 *}<I_{11}^{1 * *}\right)$ but a lower expected revenue $\left(B_{00}^{0 *}>B_{11}^{1 * *}\right)$ than the ones characterizing contracts signed by standard borrowers and standard lenders. ${ }^{18}$ This proves that, in third-best, the benefit arising from trading between social responsible agents is partially offset by the information rent appropriated by standard borrowers. However, the cost of separation would be higher if ethical banks were the unique type of lenders in the credit market (see Lemma 1) and no market segmentation was possible.

In order to verify whether the equilibrium allocation with market segmentation is also Unconstrained Interim Efficient, we consider now cross-subsidies between ethical and standard banks.

Proposition 4 Unconstrained Interim Efficiency. A sufficient condition such that the equilibrium with market segmentation is Unconstrained Interim Efficiency is $q<\frac{1}{2}$.

Proof. See Appendix 6.5.

The proof of Proposition 4 is built as follows. In order to verify whether Pareto dominating contracts with cross-subsidies between ethical and standard banks exist, we proceed again in two steps. First, we characterize the profit maximizing contract for a standard bank when the latter sign with the standard borrower a contract entailing the second-best expected profits, $p_{H} B_{00}^{0 *}$, plus a transfer $T$ to the borrower. Such a transfer now must be paid by ethical banks to standard ones. Cross subsidization between different lenders is possible if the ethical bank earns positive profits on an alternative contract $\left(B_{11}^{1^{00}}, I_{11}^{1^{\circ 0}}\right)$ (solving Program 20 in Appendix 6.5) that motivated borrowers prefer to $\left(B_{11}^{1 * *}, I_{11}^{1 * *}\right)$. Thus, in the second step, we must verify whether the Pareto improving new contract $\left(B_{11}^{1^{\circ}}, I_{11}^{1^{\circ}}\right)$ is profitable enough to cover the transfer $T$ to be paid to standard lenders. In appendix 6.5 we show that, for $q<1 / 2$, this is impossible and hence no Pareto improving contract with cross-subsidy between different lenders exists. The intuition for this result is straightforward: cross-subsidized contracts are feasible if $-T(1-q)+q E \pi_{11}^{1} \geq 0$, where

\footnotetext{
${ }^{18}$ Notice that the same relationship between equilibrium contracts exists in the second-best for $\underline{\Delta}_{\theta} \leq \Delta_{\theta} \leq \bar{\Delta}_{\theta}$ (see Proposition 1).
} 
$E \pi_{11}^{1}$ is ethical banks' expected profits from contract $\left(B_{11}^{1^{\circ}}, I_{11}^{1^{\circ}}\right)$. Obviously, a low percentage of motivated borrowers in the population (or a low value of $q$ ) is not compatible with the feasibility of cross-subsidized contracts.

Since the condition is sufficient but not necessary, larger values of $q$ are still compatible with Unconstrained Interim Efficiency. However, when $q$ becomes sufficiently larger than $1 / 2$, then the equilibrium allocation with market segmentation is not interim efficient anymore and Pareto-dominating allocations with cross-subsidies from ethical to standard banks exist. ${ }^{19}$ As explained before, a decentralized economy is not able to implement such Pareto-improving allocations because they imply cross-subsidies between different menus, i.e. they require menus that are not feasible in isolation and thus are not chosen by lenders in the second stage of the Contract Proposal Game. However, in principle the government could intervene to restore efficiency by imposing taxes to ethical banks to be used to partially finance commercial banks. Nevertheless, the political support for such a policy would reasonably be extremely low! In fact, ethical banks are sacrificing profits in the social interest by financing projects which provide positive externalities to people and communities whereas commercial banks are maximizing their profits investing in projects generating high expected returns and no positive externalities.

\section{Conclusion}

In our model two different credit markets exist: the market for standard projects and the market for ethical ones. We define ethical projects those projects with both social and economic profitability but with a lower expected revenue with respect to standard ones. We model ethical banks as lenders which are able to commit to financing only ethical projects so that they are not interested in operating in the markets for standard projects. Motivated borrowers obtain a non-monetary benefit (a premium for social responsibility) when they undertake ethical projects and also an additional benefit from trading with ethical banks in the case their project is successful. This implies that motivated borrowers prefer to trade with ethical banks as long as the contract conditions are not too unfavorable with respect to those obtained with standard lenders.

We investigate how ethical banks and motivated borrowers interact together when credit markets are competitive and also standard banks and standard borrowers are active. When moral hazard is the unique market failure, we showed in a previous paper that the matching of ethical lenders with motivated borrowers reduces the frictions caused by moral-hazard and makes motivated borrowers better off: not only they receive the premium for corporate social responsibility but they may also obtain better contract conditions, in terms of larger loans and higher expected returns, than standard borrowers.

However, when no credible commitment to borrowers' social responsibility exists and motivated entrepreneurs receive a better prospect, then standard entrepreneurs have interest in mimicking social

\footnotetext{
${ }^{19}$ Those allocations entail a payoff for motivated borrowers that is in between the minimum payoff obtained with contract $\left(B_{11}^{1 * *}, I_{11}^{1 * *}\right)$ and the maximum one implied by $\left(B_{11}^{1^{\circ \circ}}, I_{11}^{1^{\circ \circ}}\right)$.
} 
responsibility by investing in ethical projects in order to obtain the dominating contract. This is the setting we study in the present paper: we solve the Contract Proposal Game where informed borrowers offer (possibly separating) contracts to ethical and standard banks. We contribute to the literature on Informed Principals because, in our setting, agents are heterogeneous and, as a consequence, principals offer multiple menus.

We show that $(i)$ in the Contract Proposal Game with heterogeneous lenders, the equilibrium allocation entails full market segmentation and is characterized by two contracts picked from different menus. (ii) The menu offered to ethical banks contains the RSW allocation with market segmentation in which motivated borrowers pay the cost of separation from standard entrepreneurs and lose their higher expected returns. (iii) The coexistence of standard and ethical banks in the credit market improves efficiency because the RSW allocation with market segmentation dominates the one with homogeneous lenders. This means that the efficiency-loss caused by adverse selection would be higher in a credit market with homogeneous banks. (iv) The equilibrium allocation with market segmentation is always unique. $(v)$ If the share of motivated borrowers in the population of entrepreneurs is less than $50 \%$, then the equilibrium allocation with market segmentation is (Unconstrained) Interim Efficient.

In a nutshell, our model shows that market segmentation improves efficiency and solves the problem of multiplicity of equilibria in Contract Proposal Games.

\section{Appendix}

\subsection{Second-best contracts}

The net present value of both projects (ethical and non-ethical) is positive if the borrower behaves and negative otherwise. Hence, the investment cannot be implemented, in either standard or ethical projects, if it is not possible to address the moral hazard problem:

$$
\begin{aligned}
p_{H} R & >1 \\
p_{L} R+P & <1 .
\end{aligned}
$$

Moreover, the expected profit of both standard and socially responsible lenders must be non-negative. The two lenders' participation constraints $\left(I R_{0 j}^{L}\right)$ and $\left(I R_{1 j}^{L}\right)$, thus correspond to:

$$
p_{H} L_{i j} \geq I_{i j}-A
$$

or:

$$
p_{H} R I_{i j}-I_{i j}+A \geq p_{H} B_{i j}
$$

As illustrated in Barigozzi and Tedeschi (2015), the problem of a borrower contracting a loan for a 
standard project with a standard lender is:

$$
\begin{array}{ccc}
\max _{B_{00}^{0}, I_{00}^{0}} & p_{H} B_{00}^{0}-A & \\
\text { s.t. } & B_{00}^{0} \geq \frac{P I_{00}^{0}}{\Delta_{p}} & \left(I C_{00}^{B 0}\right) \\
& \left(p_{H} R^{0}-1\right) I_{00}^{0}-p_{H} B_{00}^{0}+A \geq 0 & \left(I R_{00}^{L 0}\right)
\end{array}
$$

where $\left(I C_{00}^{B 0}\right)$ is the incentive compatibility constraint for a standard borrower trading with a standard bank for a standard project and $\left(I R_{00}^{L 0}\right)$ is the participation constraint of the standard lender. The solution is contract $\left(B_{00}^{0 *}, I_{00}^{0 *}\right)$ such that:

$$
\begin{aligned}
I_{00}^{0 *} & =\frac{A}{1-p_{H}\left(R^{0}-\frac{P}{\Delta_{p}}\right)} \\
B_{00}^{0 *} & =\frac{P}{\Delta_{p}} \frac{A}{1-p_{H}\left(R^{0}-\frac{P}{\Delta_{p}}\right)}=\frac{P I_{00}^{0 *}}{\Delta_{p}}
\end{aligned}
$$

The program of a motivated borrower contracting for an ethical project with an ethical bank is very similar to (8); in particular, $R^{1}$ must replace $R^{0}$ and the incentive constraint $I C_{11}^{B 1}$, illustrated in Section 3 , must replace $I C_{00}^{B 0}$. The solution is contract $\left(B_{11}^{1 *}, I_{11}^{1 *}\right)$, such that:

$$
\begin{aligned}
I_{11}^{1 *} & =\frac{A+p_{H} \Delta_{\theta}}{1-p_{H}\left(R^{1}-\frac{P}{\Delta_{p}}\right)} \\
B_{11}^{1 *} & =\frac{P}{\Delta_{p}} \frac{A+p_{H} \Delta_{\theta}}{1-p_{H}\left(R^{1}-\frac{P}{\Delta_{p}}\right)}-\Delta_{\theta}=\frac{P}{\Delta_{p}} I_{11}^{1 *}-\Delta_{\theta}
\end{aligned}
$$

The three threshold values appearing in Proposition 1 are:

$$
\begin{aligned}
& \underline{\Delta}_{\theta} \equiv \max \left\{0, \underline{\Delta}_{\theta}-\frac{\Delta_{p}}{p_{H}^{2} P}\left(1-p_{H}\left(R^{1}-\frac{P}{\Delta_{p}}\right)\right) \theta\right\} \\
& \underline{\Delta}_{\theta} \equiv\left(R^{0}-R^{1}\right) I_{00}^{0 *} \\
& \bar{\Delta}_{\theta} \equiv \frac{p_{H} P}{\Delta_{p}} \frac{\left(R^{0}-R^{1}\right) I_{00}^{0 *}}{p_{H} R^{1}-1}=\frac{p_{H} B_{00}^{0 *}}{p_{H} R^{1}-1}\left(R^{0}-R^{1}\right)
\end{aligned}
$$

\subsection{Pooling contract}

The pooling contract that motivated borrowers propose to ethical banks, if they are not willing to pay the cost of separation from standard borrowers, can be defined as follows:

Definition 4 Suppose that motivated borrowers propose a pooling contract $\left(B_{1 j}^{1 *}, I_{1 j}^{1 *}\right)$ to ethical banks. The pooling contract solves:

$$
\begin{array}{ccc}
\max _{B_{1 j}^{1}, I_{1 j}^{1}}^{1} & p_{H} \Delta B_{1 j}^{1}+p_{H} \Delta_{\theta}+\theta-A & \\
\text { s.t. } & B_{1 j}^{1} \geq \frac{P}{\Delta_{p}} I_{1 j}^{1} & \left(I C_{10}^{B}\right) \\
& \left(p_{H} R^{S 1}-1\right) I_{1 j}^{1}-p_{H} B_{1 j}^{1}+A \geq 0 & \left(I R_{1 j}^{L 1}\right)
\end{array}
$$

or it satisfies the standard borrowers' incentive constraint and the participation constraint of ethical banks. 
Remember that, when the incentive constraint of standard borrowers holds, a fortiori the incentive constraint of motivated borrowers is satisfied. Moreover, it can be easily shown (see Barigozzi and Tedeschi $2015)$ that the sum of the two premia for social responsibility $p_{H} \Delta_{\theta}+\theta$ appearing in the objective function of (Pooling Contract), but not in the incentive compatibility constraint $I C_{10}^{B}$, does not affect the optimal contract. Thus, contract $\left(B_{10}^{1 *}, I_{10}^{1 *}\right)$ (considered in Definition 1) and $\left(B_{1 j}^{1 *}, I_{1 j}^{1 *}\right)$ are equivalent.

Standard borrowers will never choose the pooling contract $\left(B_{1 j}^{1 *}, I_{1 j}^{1 *}\right)$ because they strictly prefer the second-best contract $\left(B_{00}^{0 *}, I_{00}^{0 *}\right)$. Moreover, $\left(B_{1 j}^{1 *}, I_{1 j}^{1 *}\right)$ does not make use of the relaxed incentive constraint $\left(I C_{11}^{B}\right)$ that allows to reduce agency costs for motivated borrowers (who would be the only ones to possibly choose contract $\left.\left(B_{1 j}^{1 *}, I_{1 j}^{1 *}\right)\right)$. Thus, the separating allocations analyzed in the main text strictly dominate the pooling contract solving Program Pooling Contract.

\subsection{Proof of Lemma 2}

In order to characterize contract $\left(B_{11}^{1 * *}, I_{11}^{1 *}\right)$ in the RSW allocation with market segmentation, we have to solve the following problem of a representative motivated borrower:

$$
\begin{array}{ccc}
\max _{B_{11}^{1}, I_{11}^{1}} & p_{H} B_{11}^{1}+p_{H} \Delta_{\theta}+\theta-A & \\
\text { s.t. } & B_{11}^{1}+\Delta_{\theta} \geq \frac{P}{\Delta_{p}} I_{11}^{1} & \left(I C_{11}^{B}\right) \\
& \left(p_{H} R^{1}-1\right) I_{11}^{1}-p_{H} B_{11}^{1}+A \geq 0 & \left(I R_{11}^{L}\right) \\
& p_{H} B_{00}^{0 *} \geq p_{L} B_{11}^{1}+P I_{11}^{1} & \left(S S_{0 / 1}^{h e t}\right)
\end{array}
$$

Notice that $S S_{0 / 1}^{\text {het }}$ must be binding, otherwise the second-best program, which is not feasible by assumption, would be reached; in fact, for $\Delta_{\theta} \geq \bar{\Delta}_{\theta}$, the standard borrower prefers the motivated borrower's contract. Hence

$$
p_{H} B_{00}^{0 *}=p_{L} B_{11}^{1}+P I_{11}^{1}
$$

The three constraints in Program 12 can be rewritten as:

$$
\begin{array}{cc}
I_{11}^{1} \leq \frac{\Delta_{p}}{P} B_{11}^{1}+\frac{\Delta_{p}}{P} \Delta_{\theta} & \left(I C_{11}^{B}\right) \\
I_{11}^{1} \geq \frac{p_{H} B_{11}^{1}-A}{p_{H} R^{1}-1} & \left(I R_{11}^{L}\right) \\
I_{11}^{1} \leq \frac{p_{H}}{P} B_{00}^{0 *}-\frac{p_{L}}{P} B_{11}^{1} & \left(S S_{0 / 1}^{h e t}\right)
\end{array}
$$

In the space $\left(B_{11}^{1}, I_{11}^{1}\right)$ the boundary of the sets are straight lines. That of $S S_{0 / 1}^{h e t}$ is negatively sloped while those of the other two are positively sloped. In particular, the lines defined by $I C_{11}^{B}$ and $I R_{11}^{L}$ have positive and a negative intercept, respectively. We are going to prove that the three linear constraints are compatible with each other and, in the set of feasible allocations, we will find out which one maximizes the motivated borrower's payoff.

Suppose that $I C_{11}^{B}$ is binding and hence holds with equality. Then substituting $I C_{11}^{B}$ into $S S_{0 / 1}^{h e t}$ (which is binding) we obtain:

$$
p_{H} B_{00}^{0 *}=p_{L}\left(\frac{P}{\Delta_{p}} I_{11}^{1}-\Delta_{\theta}\right)+P I_{11}^{1}=\left(\frac{p_{L}}{\Delta_{p}}+1\right) P I_{11}^{1}-p_{L} \Delta_{\theta}=\frac{p_{H}}{\Delta_{p}} P I_{11}^{1}-p_{L} \Delta_{\theta} .
$$


Using the previous equation to derive $I_{11}^{1}$ and substituting the expression for $B_{00}^{0 *}$, we obtain an explicit expression for $I_{11}^{1}$ :

$$
\begin{gathered}
I_{11}^{1}=\frac{\Delta_{p}}{P} B_{00}^{0 *}+\frac{\Delta_{p}}{P} \frac{p_{L}}{p_{H}} \Delta_{\theta}= \\
\frac{A}{1-p_{H}\left(R^{0}-\frac{P}{\Delta_{p}}\right)}+\frac{\Delta_{p}}{P} \frac{p_{L}}{p_{H}} \Delta_{\theta}
\end{gathered}
$$

We substitute the expression for $I_{11}^{1}$ back into $I C_{11}^{B}$ to obtain the motivated borrower's income in the point where $I C_{11}^{B}$ and $S S_{0 / 1}^{\text {het }}$ cross each other:

$$
\begin{aligned}
B_{11}^{1} & =\frac{P}{\Delta_{p}}\left(\frac{A}{1-p_{H}\left(R^{0}-\frac{P}{\Delta_{p}}\right)}+\frac{\Delta_{p}}{P} \frac{p_{L}}{p_{H}} \Delta_{\theta}\right)-\Delta_{\theta} \\
& =\frac{P}{\Delta_{p}} \frac{A}{1-p_{H}\left(R^{0}-\frac{P}{\Delta_{p}}\right)}-\frac{\Delta_{p}}{p_{H}} \Delta_{\theta}
\end{aligned}
$$

We now must check whether the participation constraint of the lender is satisfied for the values of $B_{11}^{1}$ and $I_{11}^{1}$ just derived. By substituting those values into $I R_{11}^{L}$ we obtain:

$$
\begin{gathered}
\left(p_{H} R^{1}-1\right) I_{11}^{1}-p_{H} B_{11}^{1}+A= \\
-p_{H} \frac{R^{0}-R^{1}}{1+\frac{P}{\Delta_{p}} p_{H}-p_{H} R^{0}} A+\left(p_{H} R^{1}-1\right) \frac{\Delta_{p}}{P} \frac{p_{L}}{p_{H}} \Delta_{\theta}+\Delta_{p} \Delta_{\theta}
\end{gathered}
$$

which must be non-negative. Thus, $I R_{11}^{L}$ is satisfied if:

$$
\left(p_{H} R^{1}-1\right) \frac{\Delta_{p}}{P} \frac{p_{L}}{p_{H}} \Delta_{\theta}+\Delta_{p} \Delta_{\theta} \geq A p_{H} \frac{R^{0}-R^{1}}{1+\frac{P}{\Delta_{p}} p_{H}-p_{H} R^{0}}
$$

Recall that we are considering the case where $\Delta_{\theta} \geq \bar{\Delta}_{\theta}$. From (11) we know that:

$$
\bar{\Delta}_{\theta}=\frac{p_{H} P}{\Delta_{p}} \frac{\left(R^{0}-R^{1}\right) I_{00}^{0 *}}{p_{H} R^{1}-1}=\frac{p_{H} P}{\Delta_{p}} \frac{\left(R^{0}-R^{1}\right)}{p_{H} R^{1}-1} \frac{A}{1-p_{H}\left(R^{0}-\frac{P}{\Delta_{p}}\right)}
$$

Because the l.h.s of (14) is increasing in $\Delta_{\theta}$, a sufficient condition for $I R_{11}^{L}$ to be satisfied is that inequality (14) holds when substituting $\bar{\Delta}_{\theta}$ in the place of $\Delta_{\theta}$ :

$$
\begin{gathered}
\left(p_{H} R^{1}-1\right) \frac{\Delta_{p}}{P} \frac{p_{L}}{p_{H}} \frac{p_{H} P}{\Delta_{p}} \frac{\left(R^{0}-R^{1}\right)}{p_{H} R^{1}-1} \frac{A}{1-p_{H}\left(R^{0}-\frac{P}{\Delta_{p}}\right)}+ \\
p_{H} P \frac{\left(R^{0}-R^{1}\right)}{p_{H} R^{1}-1} \frac{A}{1-p_{H}\left(R^{0}-\frac{P}{\Delta_{p}}\right)} \geq \\
A p_{H} \frac{R^{0}-R^{1}}{1+\frac{P}{\Delta_{p}} p_{H}-p_{H} R^{0}}
\end{gathered}
$$

which boils down into

$$
\frac{p_{H} P}{p_{H} R^{1}-1} \geq p_{H}-p_{L}=\Delta_{p}
$$


or

$$
p_{H} \frac{P}{\Delta_{p}}-\left(p_{H} R^{1}-1\right)=1+\frac{P}{\Delta_{p}} p_{H}-p_{H} R^{1} \geq 0
$$

which is certainly true, being the previous expression the denominator of (10). Hence, the constraint $I R_{11}^{L}$ is satisfied implying that the two constraints, $I R_{11}^{L}$ and $I C_{11}^{B}$ are compatible with each other. That is, $I R_{11}^{L}$ (taken with equality) crosses $S S_{0 / 1}^{h e t}$ at a lower investment level, $I_{11}^{1}$, and (more importantly) at a bigger borrower's revenue, $B_{11}^{1}$, with respect to $I C_{11}^{B}$ (again taken with equality). This means that the solution where $I R_{11}^{L}$ and $S S_{0 / 1}^{h e t}$ cross each other is characterized by the highest $B_{11}^{1}$, in the intersection of all constraints. As can be checked in the following figure, the feasible allocations are inside the three straight lines representing the three constraints and the motivated borrower's expected revenue is maximized in the intersection of $I R_{11}^{L}$ and $S S_{0}^{B}$.

Insert Figure 1 here

The point where $I R_{11}^{L}$ crosses $S S_{0 / 1}^{h e t}$ is characterized by the system

$$
\left[\begin{array}{cc}
\left(p_{H} R^{1}-1\right) & -p_{H} \\
P & p_{L}
\end{array}\right]\left[\begin{array}{c}
I_{11}^{1} \\
B_{11}^{1}
\end{array}\right]=\left[\begin{array}{c}
-A \\
p_{H} B_{00}^{0 *}
\end{array}\right]
$$

with solutions:

$$
\begin{aligned}
I_{11}^{1} & =\frac{p_{H}^{2} B_{00}^{0 *}-p_{L} A}{p_{L}\left(p_{H} R^{1}-1\right)+p_{H} P} \\
B_{11}^{1} & =\frac{\left(p_{H} R^{1}-1\right) p_{H} B_{00}^{0 *}+A P}{p_{L}\left(p_{H} R^{1}-1\right)+p_{H} P}
\end{aligned}
$$

Substituting the value of $B_{00}^{0 *}$ we obtain:

$$
\begin{gathered}
B_{11}^{1 * *}=\frac{p_{L}\left(p_{H} R^{1}-1\right)+p_{H} P-\Delta_{p} p_{H}\left(R^{0}-R^{1}\right)}{p_{L}\left(p_{H} R^{1}-1\right)+p_{H} P} \frac{P}{\Delta_{p}} \frac{A}{1-p_{H}\left(R^{0}-\frac{P}{\Delta_{p}}\right)} \\
I_{11}^{1 * *}=\frac{p_{L}\left(p_{H} R^{1}-1\right)+p_{H} P+p_{L} p_{H}\left(R^{0}-R^{1}\right)}{p_{L}\left(p_{H} R^{1}-1\right)+p_{H} P} \frac{A}{1-p_{H}\left(R^{0}-\frac{P}{\Delta_{p}}\right)}
\end{gathered}
$$

Note that $B_{11}^{1 * *}$ and $I_{11}^{1 * *}$ do not depend on $\Delta_{\theta}$ and, by comparison with expressions in Appendix 6.1, they are such that $B_{11}^{1 * *}<B_{00}^{0 *}$ and $I_{11}^{1 * *}>I_{00}^{0 *}$. Moreover, for $\Delta_{\theta} \geq \bar{\Delta}_{\theta}$ and $B_{11}^{1 *}>B_{00}^{0 *}$, we have that $B_{11}^{1 *}>B_{00}^{0 *}>B_{11}^{1 * *}$. Finally, we showed before that the third-best contract is at the intersection between $S S_{0 / 1}^{h e t}$ and $I R_{11}^{L}$. The second-best contract is instead at the intersection between $I C_{11}^{B}$ and, again, $I R_{11}^{L}$. Since $I R_{11}^{L}$ and $S S_{0 / 1}^{h e t}$ are positively and negatively sloped (see Figure 1), respectively, it must be true that the level of investment in the third best is lower than in the second best, $I_{11}^{1 * *}<I_{11}^{1 *}$.

We proved that, at the solution of Program 12, the incentive constraint $I C_{11}^{B}$ is slack. One may then wonder whether the solution to a program where the incentive constraint of the standard (instead of the motivated) borrower is satisfied and where, in the self-selection constraint $S S_{0 / 1}$, the mimicker behaves 
(instead of misbehaving), is Pareto-superior to the allocation we just derived. To see that, let us consider the following program:

$$
\begin{array}{ccc}
\max _{B_{11}^{1}, I_{11}^{1}} & p_{H} B_{11}^{1}+p_{H} \Delta_{\theta}+\theta-A & \\
\text { s.t. } & B_{11}^{1} \geq \frac{P}{\Delta_{p}} I_{11}^{1} & \left(I C_{11}^{B}\right) \\
& \left(p_{H} R^{1}-1\right) I_{11}^{1}-p_{H} B_{11}^{1}+A \geq 0 & \left(I R_{11}^{L}\right) \\
& p_{H} B_{00}^{0 *} \geq p_{H} B_{11}^{1} & \left(S S_{0 / 1}\right)
\end{array}
$$

The answer is not. Indeed, the previous program is mathematically equivalent to the Pooling Contract analyzed in Appendix 6.2, which delivers the Pareto-dominated pooling solution $\left(B_{1 j}^{1 *}, I_{1 j}^{1 *}\right)$.

\subsection{Proof of Proposition 2}

The equilibrium allocation with market segmentation is Constrained Interim Efficient if a pair of Pareto dominating contracts financed by ethical banks and feasible in expectation does not exist.

First step. We will derive the expected profits of an ethical bank as a function of $T$, where $T$ is the standard borrowers' rent above their expected utility $p_{H} B_{00}^{0 *}$, in a candidate equilibrium with cross subsidy:

$$
\begin{array}{ccc}
\max _{B_{10}^{1}(T), I_{10}^{1}(T)} & \left(p_{H} R^{1}-1\right) I_{10}^{1}(T)-p_{H} B_{10}^{1}(T)+A & \\
\text { st. } & B_{10}^{1}(T) \geq \frac{P}{\Delta_{p}} I_{10}^{1}(T) & \left(I C_{10}^{1}\right) \\
& p_{H} B_{10}^{1}(T) \geq p_{H} \frac{P}{\Delta_{p}} \frac{A}{1-p_{H}\left(R^{0}-\frac{P}{\Delta_{p}}\right)}+T & \left(P C_{10}^{1}\right)
\end{array}
$$

$P C_{10}^{1}$ indicates that the new contract $\left(B_{10}^{1}(T), I_{10}^{1}(T)\right)$ implies, for standard borrowers, a gain of $T$ over the expected payoff obtained with $\left(B_{00}^{0 *}, I_{00}^{0 *}\right)$, where $B_{00}^{0 *}=\frac{P}{\Delta_{p}} \frac{A}{1-p_{H}\left(R^{0}-\frac{P}{\Delta_{p}}\right)}$.

The participation constraint $P C_{10}^{1}$ of the standard borrower must be binding. If not, the standard lender could decrease $B_{10}^{1}(T)$ and increase profits. By substituting $P C_{10}^{1}$ taken with equality into the objective function, the program becomes:

$$
\begin{array}{ccc}
\max & \left(p_{H} R^{1}-1\right) I_{10}^{1}(T)+\frac{1-p_{H} R^{0}}{1-p_{H}\left(R^{0}-\frac{P}{\Delta_{p}}\right)} A-T & \\
\text { st. } & B_{10}^{1}(T) \geq \frac{P}{\Delta_{p}} I_{10}^{1}(T) & \left(I C_{10}^{1}\right)
\end{array}
$$

The objective function is thus increasing in $I_{10}^{1}$. Hence, also the incentive compatibility constraint $I C_{10}^{1}$ has to be binding. As a consequence, we can study Program (15) with both constraints binding. From the $P C_{10}^{1}$ :

$$
B_{10}^{1}(T)=\frac{P}{\Delta_{p}} \frac{A}{1-p_{H}\left(R^{0}-\frac{P}{\Delta_{p}}\right)}+\frac{T}{p_{H}}
$$

and substituting $B_{10}^{1}(T)$ into $I C_{10}^{1}$ we find:

$$
I_{10}^{1}(T)=\frac{\Delta_{p}}{P} B_{10}^{1}(T)=\frac{A}{1-p_{H}\left(R^{0}-\frac{P}{\Delta_{p}}\right)}+\frac{\Delta_{p}}{P p_{H}} T
$$


Now we can replace the expressions for $B_{10}^{1}(T)$ and $I_{10}^{1}(T)$ into the objective function of the ethical bank to derive its (maximized) expected payoff as a function of the transfer $T$ :

$$
\Pi_{L_{1}}(T)=-\frac{\Delta_{p}}{P} \frac{T}{p_{H}}\left(1-p_{H}\left(R^{1}-\frac{P}{\Delta_{p}}\right)\right)-\frac{p_{H}\left(R^{0}-R^{1}\right) A}{1-p_{H}\left(R^{0}-\frac{P}{\Delta_{p}}\right)}
$$

Thus, $\Pi_{L_{1}}(T)<0 \forall T$ and $\Pi_{L_{1}}(T)=-\frac{p_{H}\left(R_{0}-R_{1}\right) A}{1-p_{H}\left(R_{0}-\frac{P}{\Delta_{p}}\right)}<0$ if $T=0$. Profits $\Pi_{L_{1}}(T)$ are decreasing in $T$. In words, ethical banks always earn negative profits (also if $T=0$ ) when offering to standard borrowers an expected payoff $p_{H} B_{10}^{1}(T) \geq p_{H} B_{00}^{0 *}+T$. In fact $R^{0}>R^{1}$ and the best contract that ethical banks can offer to standard borrowers is always dominated (i.e. $B_{10}^{1 *}<B_{00}^{0 *}$ holds), independently from the magnitude of the transfer $T$. This implies that ethical banks need very high profits from motivated borrowers to cover losses from contract $\left(B_{10}^{1}(T), I_{10}^{1}(T)\right)$.

Second step. The transfer $T$ can be offered to standard borrowers only if ethical banks earn positive profits on motivated borrowers. We have to solve a program where motivated borrowers offer a contract to ethical banks subject to the incentive compatibility constraint of motivated borrowers $I C_{11}^{B}$, the selfselection constraint $S S_{0 / 1}^{T}$ and the participation constraint for ethical banks $\widetilde{I R}_{11}^{L}$.

$$
\begin{array}{ccc}
\max _{B_{11}^{1}, I_{11}^{1}, T} & p_{H} B_{11}^{1}+p_{H} \Delta_{\theta}+\theta-A & \\
\text { s.t. } & B_{11}^{1}+\Delta_{\theta} \geq \frac{P I_{11}^{1}}{\Delta_{p}} & \left(I C_{11}^{B}\right) \\
& \left(\left(p_{H} R^{1}-1\right) I_{11}^{1}-p_{H} B_{11}^{1}+A\right) q & \left(\widetilde{I R}_{11}^{L}\right) \\
& -\left(\frac{\Delta_{p}}{P} \frac{T}{p_{H}}\left(1-p_{H}\left(R^{1}-\frac{P}{\Delta_{p}}\right)\right)+\frac{p_{H}\left(R^{0}-R^{1}\right) A}{1-p_{H}\left(R^{0}-\frac{P}{\Delta_{p}}\right)}\right)(1-q) \geq 0 & \left(S S_{0 / 1}^{T}\right) \\
p_{H} B_{00}^{0 *}+T \geq p_{L} B_{11}^{1}+P I_{11}^{1} &
\end{array}
$$

In $\widetilde{I R}_{11}^{L}$, ethical banks must earn positive profits from the fraction $q$ of motivated borrowers in order to cover the expenditure of providing $T$ to the $1-q$ standard borrowers. The expression for the expected profits $\Pi_{L_{1}}(T)$ just derived before in (16) has been substituted in $\widetilde{I R}_{11}^{L}$.

Let us focus on the three constraints of the previous program when $T=0$ :

$$
\begin{array}{cc}
B_{11}^{1}+\Delta_{\theta} \geq \frac{P I_{11}^{1}}{\Delta_{p}} & \left(I C_{11}^{B}\right) \\
\left(\left(p_{H} R_{1}-1\right) I_{11}^{1}-p_{H} B_{11}^{1}+A\right) q-\frac{p_{H}\left(R^{0}-R^{1}\right) A}{1-p_{H}\left(R^{0}-\frac{P}{\Delta_{p}}\right)}(1-q) \geq 0 & \left(\widetilde{I R}_{11}^{L}\right) \\
p_{H} B_{00}^{0 *} \geq p_{L} B_{11}^{1}+P I_{11}^{1} & \left(S S_{0 / 1}^{\text {het }}\right)
\end{array}
$$

The system taken with equality is:

$$
\begin{array}{cc}
I_{11}^{1}=\frac{\Delta_{p}}{P} B_{11}^{1}+\frac{\Delta_{p}}{P} \Delta_{\theta} & \left(I C_{11}^{B}\right) \\
I_{11}^{1}=\frac{p_{H}\left(R^{0}-R^{1}\right)}{q\left(p_{H} R^{1}-1\right)\left(1-p_{H}\left(R^{0}-\frac{P}{\Delta_{p}}\right)\right)} A-\frac{A}{p_{H} R^{1}-1}+\frac{p_{H}}{p_{H} R^{1}-1} B_{11}^{1} & \left(\widetilde{I R}_{11}^{L}\right) \\
I_{11}^{1}=\frac{p_{H}}{\Delta_{p}} \frac{A}{1-p_{H}\left(R^{0}-\frac{P}{\Delta_{p}}\right)}-p_{L} \frac{B_{11}^{1}}{P} & \left(S S_{0 / 1}^{h e t}\right)
\end{array}
$$

By comparing system (18) with system (13) analyzed in the proof of Lemma (2), we observe that the only difference is in $\widetilde{I R}_{11}^{L}$, which now has the same slope but a higher intercept. In particular the intercept 
is now larger of the term $\frac{p_{H}\left(R^{0}-R^{1}\right)}{q\left(p_{H} R^{1}-1\right)\left(1-p_{H}\left(R^{0}-\frac{P}{\Delta_{p}}\right)\right)} A>0$. This implies that the line depicted by $\widetilde{I R}_{11}^{L}$ shifts on the left with respect to the one depicted by $I R_{11}^{L}$ and illustrated in Figure 1.

We need now to understand whether $\widetilde{I R}_{11}^{L}$ crosses $I C_{11}^{B}$ on the left or on the right of the intercept between $I C_{11}^{B}$ and $S S_{0 / 1}^{\text {het }}$. To do so let us first calculate $B_{I C}^{S S}$, that is $B_{11}^{1}$ in the intercept between $I C_{11}^{B}$ and $S S_{0 / 1}^{\text {het }}$ :

$$
\frac{\Delta_{p}}{P} B_{11}^{1}+\frac{\Delta_{p}}{P} \Delta_{\theta}=\frac{p_{H}}{\Delta_{p}} \frac{A}{1-p_{H}\left(R^{0}-\frac{P}{\Delta_{p}}\right)}-p_{L} \frac{B_{11}^{1}}{P}
$$

that is:

$$
B_{I C}^{S S}=\frac{A p_{H} \frac{P}{\Delta_{p}}-\Delta_{p} \Delta_{\theta}\left(1-p_{H}\left(R^{0}-\frac{P}{\Delta_{p}}\right)\right)}{p_{H}\left(1-p_{H}\left(R^{0}-\frac{P}{\Delta_{p}}\right)\right)}
$$

Let us now calculate $B_{I C}^{\widetilde{I R}}$, that is $B_{11}^{1}$ in the intercept between $I C_{11}^{B}$ and $\widetilde{I R}_{11}^{L}$ :

$$
\frac{\Delta_{p}}{P} B_{11}^{1}+\frac{\Delta_{p}}{P} \Delta_{\theta}=\frac{p_{H}\left(R^{0}-R^{1}\right)-q\left(1-p_{H}\left(R^{1}-\frac{P}{\Delta_{p}}\right)\right)}{q\left(p_{H} R^{1}-1\right)\left(1-p_{H}\left(R^{0}-\frac{P}{\Delta_{p}}\right)\right)} A+\frac{B_{11}^{1} p_{H}}{p_{H} R^{1}-1}
$$

that is:

$$
B_{I C}^{\widetilde{I R}}=\frac{\frac{P}{\Delta_{p}}\left(p_{H} R^{1}-1\right)}{1+\frac{P}{\Delta_{p}} p_{H}-p_{H} R^{1}}\left(\frac{\Delta_{\theta}}{P} \Delta_{p}+\frac{\left(1-p_{H}\left(R^{1}-\frac{P}{\Delta_{p}}\right)\right) q-p_{H}\left(R^{0}-R^{1}\right)}{q\left(p_{H} R^{1}-1\right)\left(1-p_{H}\left(R^{0}-\frac{P}{\Delta_{p}}\right)\right)} A\right)
$$

We can easily check that $B_{I C}^{S S}>B_{I C}^{\widetilde{I R}}$ implying that $\widetilde{I R}_{11}^{L}$ crosses $I C_{11}^{B}$ on the left of the intercept between $I C_{11}^{B}$ and $S S_{0 / 1}^{h e t}$. In fact:

$$
B_{I C}^{S S}-B_{I C}^{\widetilde{I R}}=\frac{\Delta_{\theta} \Delta_{p}\left(1-p_{H}\left(R^{0}-\frac{P}{\Delta_{p}}\right)\right)\left(\Delta_{p}\left(p_{H} R^{1}-1\right)+p_{H}\left(1-p_{H} R^{1}-P\right)\right) q+p_{H}^{2}\left(R^{0}-R^{1}\right) A P}{q p_{H} \Delta_{p}\left(1-p_{H}\left(R^{0}-\frac{P}{\Delta_{p}}\right)\right)\left(1-p_{H}\left(R^{1}-\frac{P}{\Delta_{p}}\right)\right)}>0
$$

The previous inequality takes into account that

$$
\Delta_{p}\left(p_{H} R^{1}-1\right)+p_{H}\left(1-p_{H} R^{1}-P\right)>0
$$

because

$$
\begin{aligned}
\Delta_{p}\left(p_{H} R^{1}-1\right)+p_{H}\left(1-p_{H} R^{1}-P\right) & = \\
\left(p_{H}-p_{L}\right)\left(p_{H} R^{1}-1\right)+p_{H}\left(1-p_{H} R^{1}-P\right) & = \\
p_{L}-p_{H}\left(P+p_{L} R^{1}\right) & > \\
p_{L}-p_{L}\left(P+p_{L} R^{1}\right) & =p_{L}\left(1-P-p_{L} R^{1}\right)>0
\end{aligned}
$$

which comes from the inefficiency of misbehaving.

All this proves that, when $T=0$, the constraints of system 18 can be depicted as in Figure 2 below. In particular, $I C_{11}^{B}$ and $\widetilde{I R}_{11}^{L}$ cross each other before reaching $S S_{0 / 1}^{h e t}$. Then the highest payoff for motivated 
borrowers is obtained at the intersection between $I C_{11}^{B}$ and $\widetilde{I R}_{11}^{L}$, where $B_{11}^{1}$ is at the highest value compatible with the three constraints.

Insert Figure 2 here

Notice that only $\widetilde{I R}_{11}^{L}$ depends on $T$. In particular, for $T>0, \widetilde{I R}_{11}^{L}$ can be re-written as:

$$
I_{11}^{1} \geq \frac{p_{H} B_{11}^{1}-A}{p_{H} R^{1}-1}+\frac{\Delta_{p}}{P} \frac{T}{p_{H}} \frac{1-p_{H}\left(R^{1}-\frac{P}{\Delta_{p}}\right)}{p_{H} R^{1}-1} \frac{1-q}{q}+\frac{p_{H}\left(R^{0}-R^{1}\right) A}{\left(1-p_{H}\left(R^{0}-\frac{P}{\Delta_{p}}\right)\right)\left(p_{H} R^{1}-1\right)} \frac{1-q}{q}
$$

Starting from $T=0$ and by increasing $T$, the intercept rises but the slope is unchanged. Hence, by increasing $T, \widetilde{I R}_{11}^{L}$ shifts even more on the left. As a consequence, the optimal $B_{11}^{1}$ moves left along $I C_{11}^{B}$ and therefore decreases.

\subsection{Proof of Proposition 4}

The equilibrium allocation with market segmentation is Unconstrained Interim Efficient if a pair of Pareto dominating contracts with cross-subsidies between ethical and standard banks does not exist.

First step. We will derive the expected profits of a standard bank as a function of $T$, where $T$ is the standard borrowers' rent above their expected utility $p_{H} B_{00}^{0 *}$, in an allocation with cross subsidy:

$$
\begin{array}{ccc}
\max _{B_{00}^{0}(T), I_{00}^{0}(T)} & \left(p_{H} R^{0}-1\right) I_{00}^{0}(T)-p_{H} B_{00}^{0}(T)+A & \\
\text { st. } & B_{00}^{0}(T) \geq \frac{P}{\Delta_{p}} I_{00}^{0}(T) & \left(I C_{00}^{0}\right) \\
& p_{H} B_{00}^{0}(T) \geq p_{H} \frac{P}{\Delta_{p}} \frac{A}{1-p_{H}\left(R^{0}-\frac{P}{\Delta_{p}}\right)}+T & \left(P C_{00}^{0}\right)
\end{array}
$$

The right hand side of $P C_{00}^{0}$ indicates that the new contract $\left(B_{00}^{0}(T), I_{00}^{0}(T)\right)$ implies, for standard borrowers, a gain of $T$ over the expected payoff obtained with $\left(B_{00}^{0 *}, I_{00}^{0 *}\right)$, where $B_{00}^{0 *}=\frac{P}{\Delta_{p}} \frac{A}{1-p_{H}\left(R^{0}-\frac{P}{\Delta_{p}}\right)}$.

The participation constraint $P C_{00}^{0}$ of the standard borrower must be binding. If not, the standard lender could decrease $B_{00}^{0}(T)$ and increase profits. By substituting $P C_{00}^{0}$ taken with equality into the objective function, the program becomes:

$$
\begin{aligned}
& \max \left(p_{H} R^{0}-1\right) I_{00}^{0}(T)+\frac{1-p_{H} R^{0}}{1-p_{H}\left(R^{0}-\frac{P}{\Delta_{p}}\right)} A-T \\
& \text { st. } \quad B_{00}^{0}(T) \geq \frac{P}{\Delta_{p}} I_{00}^{0}(T) \quad\left(I C_{00}^{0}\right)
\end{aligned}
$$

The objective function is thus increasing in $I_{00}^{0}$. Hence, also the incentive compatibility constraint $I C_{00}^{0}$ has to be binding. As a consequence, we can study Program (19) with both constraints binding. From the $P C_{00}^{0}$ :

$$
B_{00}^{0}(T)=\frac{P}{\Delta_{p}} \frac{A}{1-p_{H}\left(R^{0}-\frac{P}{\Delta_{p}}\right)}+\frac{T}{p_{H}}
$$

and substituting $B_{00}^{0}(T)$ into $I C_{00}^{0}$ we find:

$$
I_{00}^{0}(T)=\frac{\Delta_{p}}{P} B_{00}^{0}(T)=\frac{A}{1-p_{H}\left(R^{0}-\frac{P}{\Delta_{p}}\right)}+\frac{\Delta_{p}}{P p_{H}} T
$$


Now we can replace the expressions for $B_{00}^{0}(T)$ and $I_{00}^{0}(T)$ into the objective function of the lender to derive its (maximized) expected payoff as a function of the transfer $T$ :

$$
\begin{aligned}
\Pi_{L_{0}}(T)= & \left(p_{H} R^{0}-1\right) \frac{\Delta_{p}}{P}\left(\frac{P}{\Delta_{p}} \frac{A}{1-p_{H}\left(R^{0}-\frac{P}{\Delta_{p}}\right)}+\frac{T}{p_{H}}\right)+ \\
& -p_{H}\left(\frac{P}{\Delta_{p}} \frac{A}{1-p_{H}\left(R^{0}-\frac{P}{\Delta_{p}}\right)}+\frac{T}{p_{H}}\right)+A \\
= & -\frac{\Delta_{p}}{P} \frac{T}{p_{H}}\left(1-p_{H}\left(R^{0}-\frac{P}{\Delta_{p}}\right)\right)
\end{aligned}
$$

Thus, $\Pi_{L_{0}}(T)<0$ if $T>0$ and $\Pi_{L_{0}}(T)=0$ if $T=0$. As expected, the standard bank earns negative profits when offering the transfer $T$ to the standard borrower.

Second step. The transfer $T$ can be offered to standard borrowers if ethical banks pay for it. In turn, ethical banks can afford to pay for $T$ only if they earn positive profits on motivated borrowers. In order to verify whether Pareto improving contracts with cross-subsidy between banks are feasible, we have to solve the following program where motivated borrowers offer a contract to ethical banks subject to the incentive compatibility constraint $I C_{11}^{B}$ and the self-selection constraint $S S_{0 / 1}^{T}$. Moreover, now the transfer $T$ must enter the participation constraint for ethical banks:

$$
\begin{array}{ccc}
\max _{B_{11}^{1}, I_{11}^{1}, T} & p_{H} B_{11}^{1}+p_{H} \Delta_{\theta}+\theta-A & \\
\text { s.t. } & B_{11}^{1}+\Delta_{\theta} \geq \frac{P I_{11}^{1}}{\Delta_{p}} & \left(I C_{11}^{B}\right) \\
& \left(\left(p_{H} R^{1}-1\right) I_{11}^{1}-p_{H} B_{11}^{1}+A\right) q & \\
& -\frac{\Delta_{p}}{P} \frac{T}{p_{H}}\left(1-p_{H}\left(R^{0}-\frac{P}{\Delta_{p}}\right)\right)(1-q) \geq 0 & \left(I R_{11}^{L}\right) \\
& p_{H} B_{00}^{0 *}+T \geq p_{L} B_{11}^{1}+P I_{11}^{1} & \left(S S_{0 / 1}^{T}\right)
\end{array}
$$

notice that, in $I R_{11}^{L}$, ethical banks must earn positive profits from the fraction $q$ of motivated borrowers in order to cover the expenditure of providing $T$ to the $1-q$ standard borrowers. The expression for the expected profits $\Pi_{L_{0}}(T)$ just derived before has been substituted in $I R_{11}^{L}$.

In the main text of Subsection 4.2, the solution to Program 20 has been called $\left(B_{11}^{1^{\circ 0}}, I_{11}^{1^{\circ 0}}\right)$.

We know that the solution when $T=0$ (derived in Lemma 2) lies in the intersection between $I R_{11}^{L}$ and $\left.S S_{0 / 1}^{h e t} \equiv S S_{0 / 1}^{T}\right|_{T=0}$. We want to check conditions such that a marginal transfer $T$, paid to standard borrowers, makes the expected profits of motivated borrowers decrease, or such that the derivative $\left.\frac{d B_{11}^{1}}{d T}\right|_{T=0}$ is negative. However, since the transfer $T$ enters both constraints $I R_{11}^{L}$ and $S S_{0 / 1}^{T}$ in a linear way, the derivative $\frac{d B_{11}^{1}}{d T}$ does not depend on the magnitude of $T$ as long as the solution remains in the intersection between $R_{11}^{L}$ and $S S_{0 / 1}^{T}$. 
By totally differentiating $I R_{11}^{L}$ and $S S_{0 / 1}^{T}$ we obtain:

$$
\begin{gathered}
{\left[\begin{array}{cc}
-\left(p_{H} R^{1}-1\right) & p_{H} \\
-P & -p_{L}
\end{array}\right] d\left[\begin{array}{c}
I_{11}^{1} \\
B_{11}^{1}
\end{array}\right]=} \\
{\left[\begin{array}{c}
-\frac{\Delta_{p}}{P p_{H}}\left(1-p_{H}\left(R^{0}-\frac{P}{\Delta_{p}}\right)\right) \frac{(1-q)}{q} \\
-1
\end{array}\right] d T}
\end{gathered}
$$

Hence:

$$
\frac{d B_{11}^{1}}{d T}=\frac{p_{H}\left(p_{H} R^{1}-1\right) q-\left(p_{H}-p_{L}\right)\left(1-p_{H}\left(R^{0}-\frac{P}{\left(p_{H}-p_{L}\right)}\right)\right)(1-q)}{p_{H}\left(P p_{H}+\left(p_{H} R^{1}-1\right) p_{L}\right) q}
$$

Therefore $\frac{d B_{11}^{1}}{d T}<0$ if and only if

$$
q<\frac{1}{\frac{p_{H}\left(p_{H} R^{1}-1\right)}{\left(p_{H}-p_{L}\right)\left(1-p_{H}\left(R^{0}-\frac{P}{\left(p_{H}-p_{L}\right)}\right)\right)}+1}=\bar{q}
$$

and since one can check that

$$
\left(p_{H}-p_{L}\right)\left(1-p_{H}\left(R^{0}-\frac{P}{\left(p_{H}-p_{L}\right)}\right)\right)>p_{H}\left(p_{H} R^{1}-1\right)
$$

it must be $\bar{q}>\frac{1}{2}$. Thus, $q<\frac{1}{2}$ is a sufficient condition for $\frac{d B_{11}^{1}}{d T}<0$. We can conclude that, when the solution is in the intersection between $R_{11}^{L}$ and $S S_{0 / 1}^{T}$ and $q<\frac{1}{2}$, the separating allocation with cross-subsidy is not welfare improving because motivated borrowers are worse off. It remains to see what happens when $T$ increases so much that the solution is no more in the intersection between $R_{11}^{L}$ and $S S_{0 / 1}^{T}$. The three constraints appearing in Program 20 can be rewritten as:

$$
\begin{array}{cc}
I_{11}^{1} \leq \frac{\Delta_{p}}{P} B_{11}^{1}+\frac{\Delta_{p}}{P} \Delta_{\theta} & \left(I C_{11}^{B}\right) \\
I_{11}^{1} \geq \frac{p_{H} B_{11}^{1}-A}{p_{H} R^{1}-1}+\frac{\Delta_{p}}{P} \frac{T}{p_{H}} \frac{1-p_{H}\left(R^{0}-\frac{P}{\Delta_{p}}\right)}{p_{H} R^{1}-1} \frac{(1-q)}{q} & \left(I R_{11}^{L}\right) \\
I_{11}^{1} \leq \frac{p_{H}}{P} B_{00}^{0 *}-\frac{p_{L}}{P} B_{11}^{1}+\frac{T}{P} & \left(S S_{0 / 1}^{T}\right)
\end{array}
$$

As $T$ increases, the line of the $S S_{0 / 1}^{T}$ constraint in Figure 1 moves up, while the line of $I R_{11}^{L}$ moves left. Instead, $I C_{11}^{B}$ does not move. Hence, for $T$ sufficiently big, $S S_{0 / 1}^{T}$ becomes irrelevant and the optimal contract lies on the intersection between $I C_{11}^{B}$ and $I R_{11}^{L}$. However, for a continuity argument, it would still be true that $\frac{d B_{11}^{1}}{d T}<0$. In fact $I C_{11}^{B}$ is unchanged, $I R_{11}^{L}$ moves left, and we showed before that $\frac{d B_{11}^{1}}{d T}<0$ for smaller values of $T$.

We can conclude that, by increasing the transfer $T$, the expected payoff of motivated borrowers always decreases and, thus, no profitable pair of contracts with cross-subsidies exists.

\section{References}

[1] Allen, F. and G.R. Faulhaber (1989), "Signalling by underpricing in the IPO market", Journal of Financial Economics, 23(2) 303-323. 
[2] Barigozzi F. and P. Tedeschi (2015), "Credit Markets with Ethical Banks and Motivated Borrowers", Review of Finance 19(3), 1223-1279.

[3] Becchetti L. et al. (2011a), "Credit Rationing and Credit View: Empirical Evidence from an Ethicak Bank in Italy", Journal of Money, Credit and Banking 43(6), 1217-1245.

[4] Becchetti L. et al. (2011b), "Informal collateral and default risk: do 'Grameen-like' banks work in high-income countries?", Applied Financial Economics 21, 931-947.

[5] Bénabou R. and J. Tirole (2010), "Individual and Corporate Social Responsibility", Economica 77, $1-19$.

[6] Besanko, D. and A. Thakor (1987), "Collateral and Rationing: Sorting Equilibria in Monopolistic and Competitive Credit Markets", International Economic Review 28, 671-689.

[7] Bester H. (1985), "Screening vs. Rationing in Credit Markets with Imperfect Information", The American Economic Review 75(4), 850-855.

[8] Bester H. (1987), "The role of collateral in credit markets with imperfect information", European Economic Review 31(4), 887-899.

[9] Bhattacharya, S. (1979), "Imperfect Information, Dividend Policy, and "The Bird in the Hand" Fallacy", The Bell Journal of Economics 10(1), 259-270.

[10] Bouvard M. (2014), "Real option financing under asymmetric information", The Review of Financial Studies doi: 10.1093/rfs/hhs068

[11] Cestone G., J. Lerner and L. White (2014), "The Design of Syndicates in Venture Capital", mimeo, Cass Business School.

[12] Chan Y-S. and G. Kanatas (1985), "Asymmetric Valuations and the Role of Collateral in Loan Agreements", Journal of Money, Credit and Banking 17(1), 84-95.

[13] Cornée S. and A. Szafarz (2014), "Vive la Différence: Social Banks and Reciprocity in the Credit Market", Journal of Business Ethics, 125(3), 361-380.

[14] Diamond, D. (1991), "Debt maturity structure and liquidity risk", The Quarterly Journal of Economics 106(3), 709-737.

[15] Green C.F. (1989) "Business Ethics in Banking", Journal of Business Ethics, 8(8), 631-34.

[16] Hennessy C.A., D. Livdan, and Bruno Miranda (2010), "Repeated Signaling and Firm Dynamics", The Review of Financial Studies 23(5), 1981-2023.

[17] Kitzmueller M. and J. Shimshack (2012), "Economic Perspectives on Corporate Social Responsibility", Journal of Economic Literature, 50(1), 51-84.

[18] Leland, H. and Pyle, H. (1977), "Informational Asymmetries, Financial Structure, and Financial Intermediation," Journal of Finance, 32(2), 371-387.

[19] Lynch J.J. (1991), Ethical Bank: Surviving in an Age of Default, London McMillan. 
[20] Maskin E. and J. Tirole (1992), "The Principal-Agent Relationship with an Informed Principal, II: Common Values", Econometrica, vol. 60(1), 1-42.

[21] Myers, S.C. and N.S. Majluf (1984), "Corporate financing and investment decisions when firms have information that investors do not have", Journal of Financial Economics 13(2), 187-221.

[22] Rothschild, M. and J. Stiglitz (1976), "Equilibrium in Insurance Markets: an essay on the economics of imperfect information", Quarterly Journal of Economics 90, 629-649.

[23] San José L., J.L. Retolaza and J. Gutierrez (2009), "Are Ethical Banks Different? A Comparative Analysis Using the Radical Affinity Index ”, Journal of Business Ethics, vol. 100(1), 151-173.

[24] Tirole J. (2006), The theory of Corporate Finance, Princeton and Oxford: Princeton University Press.

[25] Welch, I. (1989), "Seasoned Offerings, Imitation Costs, and the Underpricing of Initial Public Offerings", Journal of Finance, 44(2), 421-449.

[26] Wilson C. (1977), "A Model of Insurance Markets with Incomplete Information", Journal of Economic Theory 16(2), 167-207. 


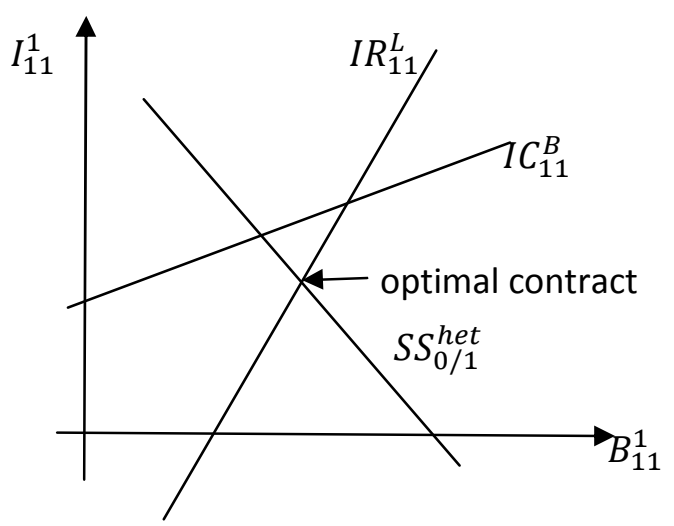

Figure 1. The RSW allocation with market segmentation: the three constraints appearing in Program RSWhet of Definition 2.

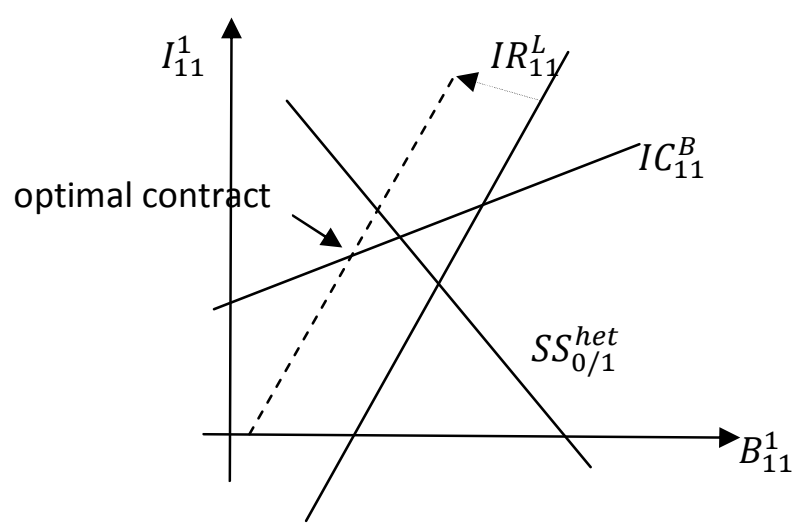

Figure 2. Separating contracts with cross-subsidies: the new participation constraint of ethical banks. 


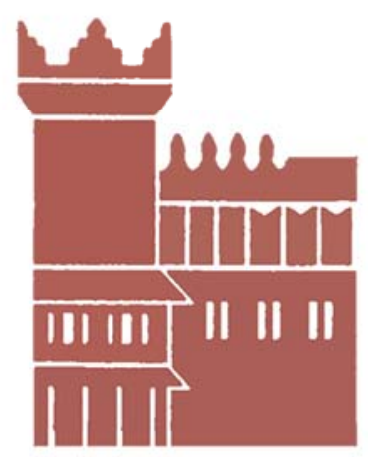

Alma Mater Studiorum - Università di Bologna DEPARTMENT OF ECONOMICS

Strada Maggiore 45

40125 Bologna - Italy

Tel. +39051 2092604

Fax +390512092664

http://www.dse.unibo.it 